\title{
EL DESLIZAMIENTO DEL 8 DE DICIEMBRE DE 1994 EN EL VOLCÁN IRAZÚ (COSTA RICA): ASPECTOS HISTÓRICOS Y GEOMORFOLOGÍA CON BASE EN FOTOGRAFÍAS AÉREAS HISTÓRICAS Y RECIENTES
}

\author{
THE DECEMBER $8^{\text {TH }} 1994$ LANDSLIDE AT IRAZÚ VOLCANO (COSTA RICA): \\ HISTORICAL ASPECTS AND GEOMORPHOLOGY BASED ON HISTORICAL \\ AND RECENT AERIAL PHOTOGRAPHS
}
Mauro Fallas ${ }^{1}$, Alejandro Prado 2 , Mauricio M. Mora*1,3, Paulo Ruiz ${ }^{1,3,4}$, Eric J. Alfaro ${ }^{5}$ y Gerardo J. Soto ${ }^{1,3}$

${ }^{1}$ Escuela Centroamericana de Geología, Universidad de Costa Rica

${ }^{2}$ Geospatial Innovations (GEOINN), San José, Costa Rica

${ }^{3}$ Red Sismológica Nacional (RSN: UCR - ICE), Universidad de Costa Rica

${ }^{4}$ Laboratorio Nacional de Materiales y Modelos Estructurales

(LANAMME-UCR), Universidad de Costa Rica

${ }^{5}$ Centro de Investigaciones Geofísicas (CIGEFI), Escuela de Física y Centro de Investigación en Ciencias del Mar y Limnología (CIMAR), Universidad de Costa Rica

*Autor para contacto: mauricio.mora@ucr.ac.cr

(Recibido: 02/10/2017; aceptado: 10/12/2017)

\begin{abstract}
On December $8^{\text {th }}, 1994$, at 22:48 (local time), a particular event took place on the northern flank of the Irazú volcano, which was described at that time as a phreatic eruption. Recently, the volcanic nature of this event was questioned and it was proposed that it would have been a debris avalanche generated by a landslide. In this work we studied this process from the historical, geological and geomorphological perspective. The hypothesis of the landslide is reinforced based on seismological evidences, although it is still not ruled out that geothermal activity could have been involved. In this work, the photogrammetric restitution was made from aerial photographs obtained by the National Geographic Institute (IGN) on December $20^{\text {th }}, 1994$, by which a volume of sliding material between $21 \pm 8$ and $22 \pm 7 \times 10^{6}$ $\mathrm{m}^{3}$ was estimated.

Keywords: Phreatic explosion, debris avalanche, photogrammetry, Irazú, landslide, Costa Rica.
\end{abstract}


RESUMEN: E1 8 de diciembre de 1994, a las 22:48 (hora local), tuvo lugar en el flanco norte del volcán Irazú un evento particular, que se describió en esa época como una erupción freática. Recientemente, se cuestionó la naturaleza volcánica de este evento y se propuso que habría sido una avalancha de escombros generado por un deslizamiento. En este trabajo se retomó el análisis de este proceso desde la perspectiva histórica, geológica y geomorfológica, y se reforzó dicha hipótesis a la luz de evidencias sismológicas, aunque sigue sin descartarse que hubiera intervenido actividad geotermal. En este trabajo se realizó la restitución fotogramétrica a partir de fotografías aéreas obtenidas por el Instituto Geográfico Nacional (IGN) el 20 de diciembre de 1994, mediante la cual se estimó un volumen deslizado entre $21 \pm 8$ y $22 \pm 7 \times 10^{6} \mathrm{~m}^{3}$.

Palabras clave: Explosión freática, avalancha de escombros volcánicos, fotogrametría, Irazú, deslizamientos, Costa Rica.

\section{INTRODUCCIÓN}

La investigación geomorfológica, a partir de modelos de elevación digital (MED), es cada día más utilizada gracias a los avances en la tecnología de posicionamiento global y el desarrollo de sistemas de información geográficos. Esto ha permitido mejorar las descripciones de superficies topográficas y efectuar análisis multitemporales que permiten observar los cambios de una superficie del terreno en el tiempo. Estos análisis se realizan actualmente con imágenes digitales, sin embargo, la necesidad de ampliar el rango temporal a épocas históricas necesita de la utilización de fotografías aéreas de archivo, obtenidas mediante técnicas analógicas. Los estudios multitemporales han sido aplicados en grandes cadenas montañosas (Zanutta, Baldi, Bitelli, Cardinali y Carrara, 2006; Fabris, Menin y Achilli, 2011; Micheletti, Lane y Chandler, 2015), o en volcanes activos tanto para el estudio de procesos gravitacionales o bien deformación cortical producto de la actividad tectónica y volcánica (Zlotnicki, Ruegg, Bacheley y Blum, 1990; Baldi, Fabris, Marsella y Monticelli, 2005; Baldi, Fabris, Marsella, Monticelli y Achilli, 2006; Baldi, Cenni, Fabris y Zanutta, 2008).

En este trabajo se estudia del deslizamiento ocurrido el 8 de diciembre de 1994 en el flanco N del volcán Irazú, Costa Rica, a partir de la restitución fotogramétrica de fotografías aéreas del Instituto Geográfico Nacional de Costa Rica (IGN), tomadas el 20 de diciembre de 1994. El trabajo se complementa con imágenes aéreas georreferenciadas obtenidas por AERODIVA S.A.
(2015), cuyo propósito era caracterizar el deslizamiento que actualmente está activo en flanco WSW del volcán Irazú, donde se encuentran varias torres de telecomunicaciones. El análisis del deslizamiento de 1994 se aborda también desde una óptica histórica, a partir información documental, hemerográfica y científico-técnica de la época (meteorológica, sismológica y volcanológica).

\section{El área de estudio}

El volcán Irazú, con una elevación de 3432 m s.n.m, se ubica en la Cordillera Volcánica Central, al noreste de la ciudad de Cartago, una de las ciudades que forma parte del Gran Área Metropolitana (GAM) de Costa Rica, la cual constituye el centro socio-económico del país (Fig. 1). Las mayores erupciones de este macizo, conocidas hasta el momento son: 1723-24 (estromboliana-freatomagmática), 1917-20 (básicamente freática y freatomagmática), 1933, 1939-40 (freatomagmática-estromboliana) y 1963-65 (estromboliana - freatomagmática). Otras posibles erupciones menores que no han sido muy bien confirmadas son: 1550-60? (incierta), 1775, 1821 y 1842 (Alvarado, 1993; Alvarado, 2009). Como resultado se obtendrían lapsos de retorno de actividad entre 6 y 67 años, aunque según Alvarado (1993) las erupciones del Irazú ocurren de manera aleatoria, sin ninguna periodicidad. Soto y Sjöbohm (2015), en contraste, determinaron que para las erupciones con Índice de Explosividad Volcánica de 3 (similares a las de 1723 y 1963), hay una periodicidad 


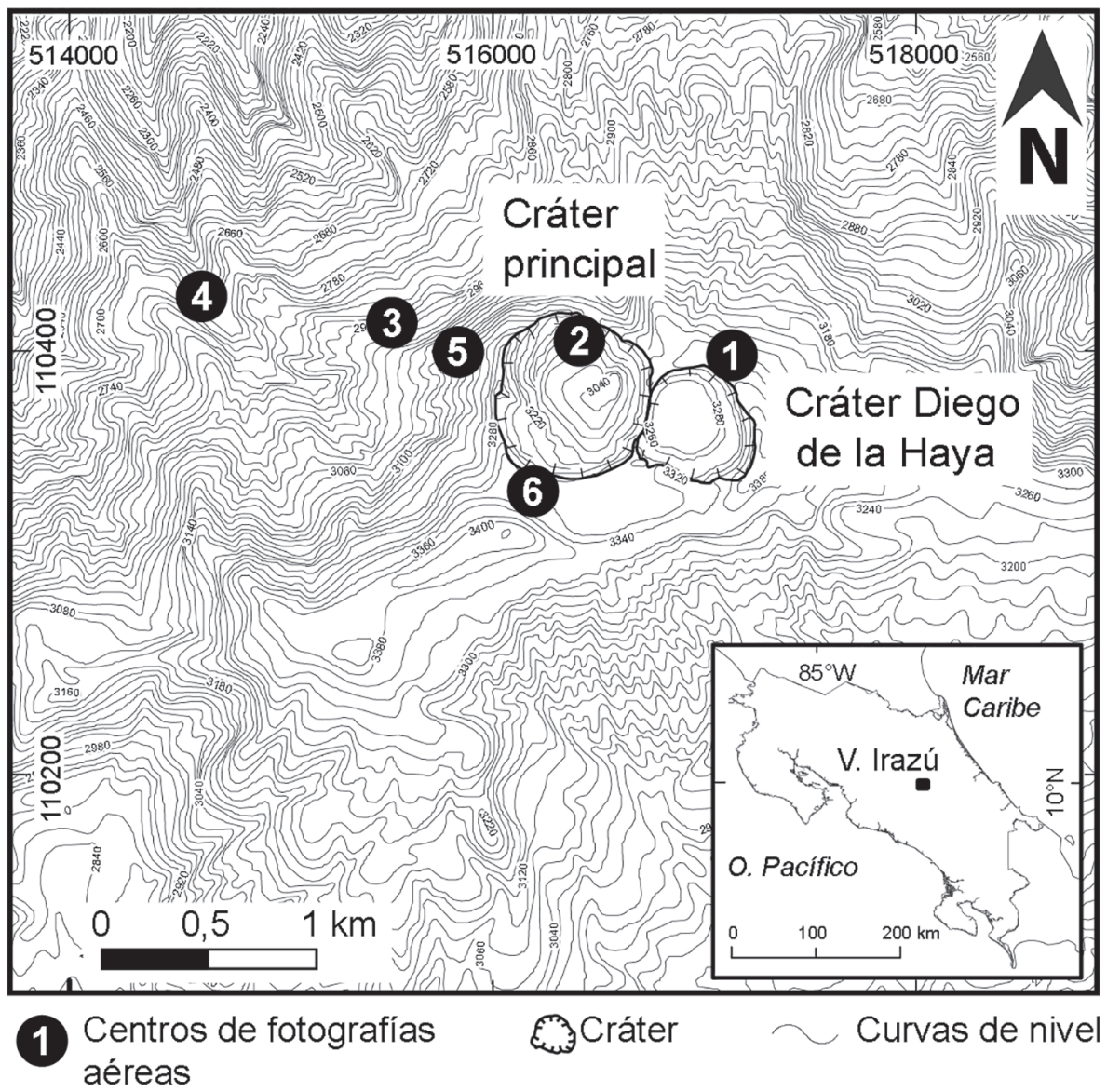

Fig. 1: Ubicación del área cuspidal del volcán Irazú (Cartago, Costa Rica) la cual es estudiada en este trabajo con énfasis en el deslizamiento del 8 de diciembre de 1994. Los círculos con los números representan los centros de las fotografías aéreas obtenidas por el Instituto Geográfico Nacional de Costa Rica (IGN) tomadas el 20 de diciembre de 1994, que se utilizaron en este estudio. Base topográfica de la hoja Istarú 1:50 000 del Instituto Geográfico Nacional (IGN). Proyección CRTM05 y datum WGS84.

de 200 a 400 años (a mediano plazo), en tanto que las erupciones menores (a corto plazo) se repiten cada 50 años aproximadamente en promedio. Soto y Sjöbohm (2015) agregan que las erupciones subplinianas, ocurrirían en periodos de recurrencia del orden de $10^{4}$ años. El detalle eruptivo explosivo conocido, sin embargo, no se extiende más allá de 2500 años antes del presente, según el trabajo de Clark, Reagan y Trimble (2006).

Hay reportes de actividad fumarólica, pero no eruptiva, en 1847, 1870, 1880, 1884, 1887 y 1910. Posterior a 1965 se generó actividad sísmica en diciembre de 1967, actividad freática y fumarólica en marzo de 1977 y mayo de 1978
(Alvarado, 1993). En las últimas décadas la actividad en el volcán Irazú ha estado marcada por una tenue actividad fumarólica en el flanco norte muy cerca de la cima, variaciones tanto del nivel, como el color de la laguna intra-cratérica y principalmente enjambres sísmicos generados por los múltiples fallamientos corticales que cortan el macizo y posible movimiento de magma y en el sistema hidrotermal (1991-92, por ejemplo).

La geomorfología del flanco N del Irazú refleja una erosión intensa caracterizada por movimientos gravitacionales de grandes dimensiones. Alvarado (1987, 1993) había caracterizado esta zona como de potencial alto para la generación 
de deslizamientos y la formación de un nuevo cráter. Por otra parte, Peraldo y Rojas (2000) señalan que la vertiente del Caribe es una zona de alto potencial de deslizamientos debido a las condiciones climáticas del área. Es en este contexto que resalta un evento particular acaecido en el año 1994, a las 22:48 el cual fue descrito en la literatura volcanológica de aquel entonces como una erupción freática, la cual generó deslizamientos y consecuentes lahares, así como una nube de ceniza que se dispersó hacia el oeste del volcán (Fernández, et al., 1994; Barquero, et al., 1995a; Mora, 1997; Barquero, 1998; Siebert, Simkin y Kimberly, 2010). Esta interpretación fue cuestionada recientemente por Alvarado, Mora y Ulloa (2013), quienes no encuentran evidencias de que el proceso tuviera una naturaleza eruptiva y, en su lugar proponen que se trata de una avalancha de escombros volcánicos producto del deslizamiento de un sector al norte del cráter principal, muy cercano a la cima, y que la nube de polvo acompañante habría sido generada por la autofragmentación de los bloques rocosos de la avalancha.

\section{MÉTODO}

Este trabajo se divide en dos partes, la primera integra el estudio del contexto histórico y narrativa del evento, generados a partir de: 1) los informes técnicos y artículos científicos relacionados con el tema del evento del 8 de diciembre de 1994 y aspectos asociados, 2) revisión de la información hemerográfica de la época, ubicada en la Biblioteca Carlos Monge Alfaro, de la Universidad de Costa Rica y la Biblioteca Nacional de Costa Rica, la cual es considerada en este trabajo como fuente secundaria, 3) la consulta del Fondo documental digitalizado José Fidel Tristán, asequible desde el cibersitio del Archivo Nacional de Costa Rica. Complementariamente se analizó el contexto hidrometeorológico de la época mediante los registros de precipitación diaria del 3 al 9 de diciembre de 1994 obtenidos a partir de 51 estaciones del Instituto Meteorológico Nacional (IMN) y del Instituto Costarricense de Electricidad (ICE), disponibles en los archivos del Centro de Investigaciones Geofísicas
(CIGEFI) de la Universidad de Costa Rica, así como las descripciones climáticas contenidas en el Boletín Meteorológico Mensual del IMN, para noviembre y diciembre de 1994 (Alvarado, 1994; Vega, 1994).

La segunda parte integra el análisis geomorfológico enfocado en la pared norte del cráter principal y la cúspide del volcán Irazú, a partir de ortofotos generadas por vuelos fotogramétricos efectuados por AERODIVA S.A. en marzo del 2015 para generar una geomorfología actual, y también a partir de fotografías aéreas obtenidas por el IGN durante un vuelo realizado el 20 de diciembre de 1994, 12 días después del deslizamiento ocurrido en ese mismo mes. Se utilizaron técnicas fotogramétricas con el propósito de generar un modelo de elevación digital (MED) con base en las fotografías aéreas históricas, con el fin de estimar el volumen deslizado.

\section{CONTEXTO HISTÓRICO - GEOLÓGICO DEL EVENTO DEL 8 DE DICIEMBRE DE 1994}

\section{Referencias históricas y recientes sobre el sector N y NW del cráter activo del volcán Irazú}

El área de la pared norte del cráter activo del volcán Irazú fue conocida históricamente como "Volcán Nuevo" según se desprende de las numerosas descripciones hechas por el científico y educador José Fidel Tristán, una de ellas su artículo titulado "The Activity of the Volcano Irazú in Costa Rica" publicado en 1923, en donde refiere que ese lugar se conocía con ese nombre desde 1886 . Por otra parte en el documento titulado "Lugares poco conocidos del volcán Irazú", con fecha del 5 de junio de 1910, el mismo Tristán junto con Alberto Rudín, hace una descripción bastante detallada del sitio, de la cual se puede rescatar lo siguiente: La parte activa hoy del Volcán Irazú queda situada al Norte
del antiguo cráter conocida con el nombre de "Volcán Nuevo".
No representa esta parte un verdadero cráter. Su forma general
es la de un gran triangulo cuyo vértice está muy al Norte en la
parte mas baja y cuya base al Sur está formada por escarpadas
rocas, que limitan el antiguo cráter. Estas rocas, han sufrido 
gradualmente, por derrumbes grandes cambios, rodando hacia la parte baja inmensas cantidades de materiales volcánicos, donde poco á poco son arrastrados por los torrentes que se forman en la época de las lluvias.

Al pie de los elevados paredones principian los grandes y a veces profundos canjilones, que dan muestras evidentes, de una poderosa erosion ayudada sin duda por la acción desintegrante de los gases sulfurosos. Estos canjilones siguen la dirección general de la pendiente es decir de Sur à Norte y van a reunirse en la parte mas baja, donde la vegetación recobra todo su vigor. En el fondo de estos canjilones se ven otros delgados hilitos de agua que siguen el fondo de los canjilones. El viajero querrá apagar la sed, que ya se siente después de algunas horas de haber dejado la fuente de Chicoa, pero, imposible! Esta agua tan cristalina y que parece pura tiene un sabor agrio pronunciado Toda el agua que haba por estos canjilones se reúne, en el lugar donde terminan las solfataras, y sigue por una profunda hondonada llena de arbustos y matorrales à reunirse con las turbias aguas del Rio Sucio" (Tristán y Rudín, 1910, p. 2-3).

Más recientemente, Alvarado (1987, 2009) se refiere a esta zona como "Las Fumarolas" y actualmente es conocido como "Volcancito". Tanto desde los escritos de José Fidel Tristán como en décadas recientes, en ese lugar se habla de la presencia de fumarolas de baja temperatura, generalmente a unos $95^{\circ} \mathrm{C}$. Gawarecki, Moxham, Morgan y Parker (1980) delimitaron 5 áreas de anomalías termales, de las cuales tres se ubican al noroeste del cráter principal, otras dos al noreste, en donde detectaron menos actividad. Alvarado (2009) había descrito en detalle este campo fumarólico en 1979, compuesto por cuatro solfataras con temperaturas entre los 85 y $93^{\circ} \mathrm{C}$. Barquero, Soto y Lesage (1992) realizan una nueva descripción de este campo de fumarolas en 1991. Según estos autores, estas fumarolas se encuentran a lo largo de valles profundos excavados en piroclastitas que sobreyacen lavas, en un ambiente altamente hidrotermalizado, específicamente en tres contextos geológicos: 1) Fracturas abiertas paralelas a los frentes de deslizamiento, 2) en paredones rocosos y 3) a lo largo de los planos de estratificación de los piroclastos.

Ulloa, Campos-Fernández y Rojas (2013) describen extensamente la mineralogía de dos cuevas que se encuentran en el flanco NW del volcán Irazú, al pie del área deslizada el 8 de diciembre de 1994, las cuales denomina "Los Mucolitos" y
"Los Minerales". También proponen que el origen de la primera podría estar asociado a espacios entre bloques de roca deslizada que habría sido limpiado por efecto de la desgasificación, en tanto la segunda estaría ligada con un deslizamiento de bloques en superficie escalonada.

Tristán y Rudín (1910) y Tristán (1921) hacen referencia a cavidades grandes en el sector NW con mucha actividad, las cuales podrían estar asociadas con la formación de las actuales cuevas, luego de varios procesos de deslizamientos y caídas de rocas. Las describen como sigue:

...Además de las solfataras, existen dos o tres lugares que presentan fenómenos de gran interés. Nos referimos á ciertas cavidades de unos $6 \mathrm{~m}$. de diámetro en cuyo fondo hierve una masa espesa de lodo de color gris. Una de estas se encuentra en el bosque al Oeste de las solfataras y de tiempo en tiempo se ven salir entre las ramas de los árboles grandes cantidades de vapor de agua. Este fenómeno se había observado antes y nuevamente lo vimos el 20 de abril próximo pasado. Otra de estas cavidades, se encontraba al pié de la peña, también con lodo hirviente... (Tristán y Rudín, 1910, p. 5).

El flanco norte del volcán Irazú, particularmente el área que comprende la cuenca alta del río Sucio, ha sido históricamente un área muy inestable y en de la cual hay reportes históricos de procesos gravitacionales tales como deslizamientos y caídas de rocas. Peraldo y Rojas (2000), en su catálogo de deslizamientos elaborado para el periodo de 1874-1960, indican que en el área comprendida por la hoja topográfica Istarú 1:50 000 del IGN, que comprende gran parte del volcán Irazú, incluyendo su cúspide y la parte superior del flanco $\mathrm{N}$ del macizo volcánico, se acumula un total de 120 deslizamientos. Ellos ponen en evidencia, además, una relación directa entre la precipitación y los deslizamientos reportados por mes en la vertiente del Caribe, en donde los meses de julio, noviembre y diciembre presentan la mayor cantidad de deslizamientos, lo cual es potenciado por la ausencia de una época seca en esa vertiente que produce elevados porcentajes de humedad en los suelos. Peraldo y Rojas (2000) encuentran dos referencias específicas de deslizamientos en la cúspide del volcán Irazú: la primera es del 16 de julio de 1902, cuando "Se informa 
que cerca de la laguna del volcán Irazú, se han abierto enormes grietas y hay señales palpables de que el terreno se va desquisiando" (Prensa Libre, 16 de julio, 1902); la segunda referencia data de El Noticiero (8 de setiembre de 1903), cuando se reportaron grandes deslizamientos del lado $\mathrm{NE}$ del volcán Irazú, probablemente debido a las fuertes lluvias. Con respecto a este segundo evento, dichos autores rescatan una información interesante del 23 de octubre de 1903, que indica que “... año tras año, especialmente en las lluvias de octubre y noviembre, vienen sucediendo nuevos derrumbes en la falda norte del volcán Irazú..." (El Noticiero, 23 de octubre de 1903); en la misma noticia se hace referencia a la cuenca del río Sucio:

...La estructura geológica de este lugar es única en Costa Rica ... debido a lo quebrado del terreno formando una en realidad un cordón contínuo de desfiladeros y a la calidad del terreno que está compuesto por de una especie de piedra de color rojizo chocolate muy deleznable al agua. En estos desfiladeros nacen multitud de ríos que juntos forman el Río Sucio que también llama la atención por el color y sabor de sus aguas... (El Noticiero, 23 de octubre, 1903).

Posteriormente, Tristán (1910) describe que debido al terremoto del 13 de abril de 1910, a las 12:37 a.m., la atención del público se enfocó en el volcán Irazú e incluso los daños provocados le fueron atribuidos al macizo, debido la creencia fuertemente enraizada de la relación entre sismos severos y las erupciones volcánicas, la cual era alimentada por la prensa de la época que constantemente hacía reportes sobre erupciones fantásticas del volcán Irazú. En consecuencia, nos narra Tristán (1910), algunos visitantes dieron información de que un nuevo cráter se había formado en el "Volcán Nuevo", en su pared externa. Por esa razón dicho autor efectuó una expedición el 20 de abril de 1910 acompañado del profesor Alberto Rudín. Como resultado, Tristán (1910) indica que el cráter viejo se encontraba en calma y lo que se suponía que era un nuevo cráter, consistía en un deslizamiento en una solfatara en el "Volcán Nuevo", situado directamente en la base de la pared norte del cráter principal.

Asimismo, Tristán y Rudín (1910) en el documento "Lugares poco conocidos del volcán Irazú" describe la caída de rocas en el sector del "Volcán Nuevo" como sigue:

...En nuestra visita la encontramos completamente aterrada y en los alrededores gran cantidad de piedras y rocas de todo tamaño. Esto fué debido á un derrumbe colosal de unos $60 \mathrm{~m}$. de altura, que ocurrió mucho tiempo antes del temblor del 13 de abril. Nos hace pensar así el hecho de encontrar las plantas arrancadas por el derrumbe ya secas, sin hojas y algunas plantitas nuevas sobre los escombros...” (Tristán y Rudín, 1910, p. 5-6).

Existe adicionalmente un reporte del gobernador Arcadio Quirós al Ministerio de Gobernación recibido en San José el 15 de abril de 1910 a las 07:00 p.m. (Quirós, 1910), que indica lo siguiente:

De Tierra Blanca mandé una Comisión al Volcán Irazú y me informa en la forma siguiente: "Los Suscritos que integramos la comisión que fue al Volcán se encuentran el derrumbe siguiente: 100 metros de largo y 50 de ancho poco más i menos encontrándose tres chimeneas al pie del peñón donde sube el vapor al alto y cae el agua. Esto queda en el nacimiento del Río Sucio. No hay otra cosa de novedad (f) La comisión- El Aj. P. José B. Garita"

Aunque no hace referencia explícita a si se trata del sector conocido como "Volcán Nuevo", es probable que se trate de esa área por la referencia a las tres chimeneas.

Peraldo y Rojas (2000) encuentran otras referencias sobre deslizamientos, una el 4 de mayo de 1910 cuando se habla de deslizamientos grandes en el volcán Irazú y el 24 de junio de 1910, cuando reporta un deslizamiento en Camino Carrillo (San Jerónimo de Moravia) que cayó en el cauce del río Sucio.

\section{Contexto sísmico y tectónico}

El macizo del volcán Irazú es cortado por múltiples fallas activas, las cuales habrían generado varios enjambres y eventos sísmicos importantes, como el que tuvo lugar el 30 de diciembre de 1952, conocido como el Terremoto de Patillos, el cual fue estudiado por Montero y Alvarado (1995). Estos autores estudiaron el fallamiento en el flanco NW del Irazú y describen algunas estructuras importantes, entre las cuales sobresale la Falla Río 
Sucio. Linkimer (2003) y Montero (2003) analizan posteriormente las áreas del Irazú y Turrialba y detallan el trazado del fallamiento y exponen evidencias geomorfológicas y geológicas de los movimientos recientes. Montero (2003), particularmente, propone un modelo tectónico mediante el cual define el sistema de falla Atirro-Río Sucio compuesto por un conjunto de fallas neotectónicas de rumbo NW, predominantemente dextrales. El mismo autor propone que entre las fallas AtirroTucurrique y la falla Río Sucio se desarrolló una cuenca de tracción (pull-apart) que denominó Turrialba-Irazú.

En este contexto tectónico complejo, en el macizo del volcán Irazú han ocurrido varias crisis sísmicas en los años 1982, 1987, 1991, 1994, 1997, 2012 y 2015. Durante el enjambre sísmico de 1991, que se extendió por varios meses, se registraron más de 3000 eventos y fue inducido por los terremotos ocurridos el 22 de diciembre de 1990 y el 22 de abril de 1991, conocidos como el Terremoto de Piedras Negras y el Terremoto de Limón, respectivamente (Barquero, et al., 1992; Barquero, Lesage, Métaxian, Creusot y Fernández, 1995; Fernández, Mora y Barquero, 1998).

Entre finales de octubre y la primera mitad de noviembre de 1994, la actividad sísmica se incrementó. Barquero et al. (1995a) reportó una serie de sismos tectónicos que fueron localizados entre los volcanes Irazú y Turrialba a profundidades entre los 1 y $12 \mathrm{~km}$ y magnitudes inferiores a 3,2 grados. Por su parte, Fernández et al. (1994) indicaron que a partir del 27 de octubre hubo un incremento en la sismicidad de baja frecuencia y tectónica. Esta última fue localizada, según Fernández et al. (1994), a distancias entre los 0,5 y $10 \mathrm{~km}$ del cráter principal, en el segmento NW de lo que ellos denominaban la falla de Irazú, la cual tiene una orientación NW-SE. La mayor parte de los sismos se localizaron a $<10 \mathrm{~km}$ de profundidad y con magnitudes entre los 2,0 y 3,4 grados. El enjambre finalizó el 18 de noviembre (Global Volcanism Program, 1994b). Para inicios de noviembre de 1994 se reportó que personas que habitaban cerca del flanco $\mathrm{N}$ del volcán Irazú sobre ruidos, que provenían de ese sector (Global Volcanism Program, 1994c). El 8 de diciembre de 1994 ocurrió el evento que fuera interpretado como actividad freática y luego del cual se registró actividad sísmica que fue disminuyendo progresivamente hasta el 14 de diciembre de ese año (Barquero, et al., 1995a).

En años subsiguientes, entre el 15 y el 18 de junio de 1997 se generó un enjambre sísmico a profundidades entre los 1 y $14 \mathrm{~km}$ y magnitudes entre los $\mathrm{Mc}=1,0$ y 4,1 (Mora, Barquero, Rojas y Fernández, 1997; Fernández, et al., 1998). Más recientemente, luego del Terremoto de Sámara, ocurrido en el año 2012, se generó una importante sismicidad inducida (Mora, Taylor y Soto, 2012). Las últimas crisis sísmicas se han generado durante febrero, mayo y julio de 2015, a lo largo de un sistema de fallas con rumbo NW-SE ubicadas en el sector oeste (Müller, Pacheco, Avard y Martínez, 2015; Avard, et al., 2015). Ha habido sismicidad también en 2016 y 2017, en varios sectores cercanos a la cima.

\section{Contexto volcanológico}

Luego de la última actividad freática que tuvo lugar en los años setenta del siglo XX (Alvarado, 1993), en las últimas décadas el volcán Irazú ha mantenido un largo periodo de calma, que solo fue interrumpido en el año 1991, cuando en la segunda semana de junio de 1991, un nuevo conjunto de fumarolas se formaron en los sectores NE, N, NW y S del cráter (Global Volcanism Program, 1991). Barquero et al. (1992) reportaron cambios importantes en la actividad hidrotermal, de la química de las fumarolas cratéricas y de la laguna, no así de las fumarolas del flanco NW, cuyas temperaturas se mantuvieron en el rango de los $75^{\circ}-95^{\circ} \mathrm{C}$, valores que se venían reportando desde las visitas efectuadas por José Fidel Tristán a inicios del siglo XX y durante la década de 1980. Adicionalmente, Barquero et al. (1992) describieron cambios en la actividad sísmica, en la cual hubo un aumento en la cantidad de sismos de baja frecuencia, principalmente a mediados de agosto de $1991 \mathrm{y}$ el registro de tremores. Estos cambios obedecieron a la desestabilización del sistema hidrotermal inducido por los terremotos del 22 de diciembre de 1990 y el 22 de abril de 1991 y, por lo tanto, la 
hipótesis de una intrusión magmática somera sería poco plausible para explicar esos cambios observados (Barquero, et al., 1992; Barquero, et al., 1995b; Despine, 1996).

Durante la primera mitad del año 1992 todavía el sistema hidrotermal se encontraba inestable, por lo que aún se registraba algo de sismicidad de baja frecuencia y había una actividad fumarólica importante en el interior del cráter principal (Barquero, 1992). Durante la segunda mitad de 1992 y el año 1993 la actividad en el Irazú era baja y con actividad sísmica esporádica (Barquero, 1992; RSN, 1994a; Global Volcanism Program, 1994a). En el año 1994 se reportó un aumento en el número, tamaño y vigorosidad en las fumarolas del interior y de la pared NW del cráter principal durante el mes de enero (Global Volcanism Program, 1994). Sin embargo, durante los meses subsiguientes no se reportaron cambios significativos y no es sino hasta octubre y noviembre de 1994 en que ocurre el enjambre, tanto en el sector N del Irazú y en el sector entre este y el volcán Turrialba, pero sin que se reportaran cambios en la actividad del sistema hidrotermal (Fernández, et al., 1994; Barquero, et al., 1995a). Galindo et al. (2004) llevaron a cabo mediciones de gas difuso en el 2001 y midieron flujos superiores a los $300 \mathrm{~g} \mathrm{~m}^{-2} \mathrm{~d}^{-1}$ en las fumarolas del flanco $\mathrm{N}$, en donde el $90 \%$ del $\mathrm{CO}_{2}$ procede de los sedimentos calcáreos incorporados en el proceso de la subducción, en tanto un $6 \%$ tiene un origen orgánico y el $4 \%$ restante tiene origen mantélico.

\section{Contexto hidrometeorológico}

\section{La Tormenta Tropical $N^{\circ} 12$ y posterior Huracán Gordon}

A partir del 4 de noviembre de 1994, un sistema de baja presión afectó la región central y norte de Costa Rica. Seguidamente, desde el 8 de noviembre de ese mismo año, ese fenómeno se constituyó en la Depresión Tropical №12, la cual se convirtió en la tormenta tropical "Gordon" el 10 de noviembre a las 1800 UTC cerca de la costa caribe de Nicaragua (Halpert, Bell, Kousky y Ropelewski, 1995; Ávila y Rappaport, 1996; Pitts, 2001). Esta tormenta tuvo una trayectoria inusual y errática sobre el Caribe, Florida y el SW del Atlántico (Pitts, 2001). Esta tormenta tropical tuvo una duración de 13 días (9-21 de noviembre), por encima del promedio de 6,5 días que registró la temporada de huracanes en 1994 (Capel Molina, 1996). Dicha tormenta provocó un temporal en la vertiente pacífica de Costa Rica del 3 al 10 de noviembre, que generó daños importantes en la vertiente del Caribe (CNE, 1994). Las condiciones antes descritas por Vega (1994), ocasionaron que la mayoría de estaciones meteorológicas en el país registraran superávits en sus acumulados mensuales, que oscilaron entre el 1 y el $18 \%$ en la vertiente del Caribe y la Zona Norte.

\section{Temporal del mes de diciembre de 1994}

Durante el mes de diciembre, en Costa Rica son comunes los vientos alisios de moderada intensidad, bloqueos anticiclónicos, frentes fríos (o en su defecto líneas de cortante), vaguadas y bajas segregadas en la parte alta de la atmósfera. Cualquiera de estos fenómenos, o la combinación de ellos, pueden tener la capacidad de desarrollar un temporal en la vertiente del Caribe de Costa Rica (Alvarado, 1994; Fallas y Oviedo, 2003). Por temporal se entiende una condición de cielo nublado durante varios días, con al menos 24 horas seguidas de lluvia persistente, a cualquier hora del día, y de intensidad variable (Fallas y Oviedo, 2003).

Según Alvarado (1994), un temporal afectó la vertiente del Caribe de Costa Rica, principalmente entre el 6 y el 14 de diciembre de 1994, el cual causó fuertes y continuas lluvias que afectaron principalmente el centro y sur de la provincia de Limón debido a los desbordamientos de los ríos e inundaciones. En el resto del país las condiciones fueron mucho menos lluviosas. Del total de lluvia mensual en Limón, el $88 \%$ se registró durante los nueve días del temporal (del 6 al 14 de diciembre de 1994), en donde para esa fecha, las lluvias superaron en más del $50 \%$ el acumulado medio mensual, es decir, llovió el doble de lo esperado estadísticamente (Alvarado, 1994). La figura 2 muestra la precipitación acumulada en el país del 3 al 9 de diciembre. Nótese que la mayor cantidad de precipitación se observó en la vertiente del Caribe y la zona norte de 


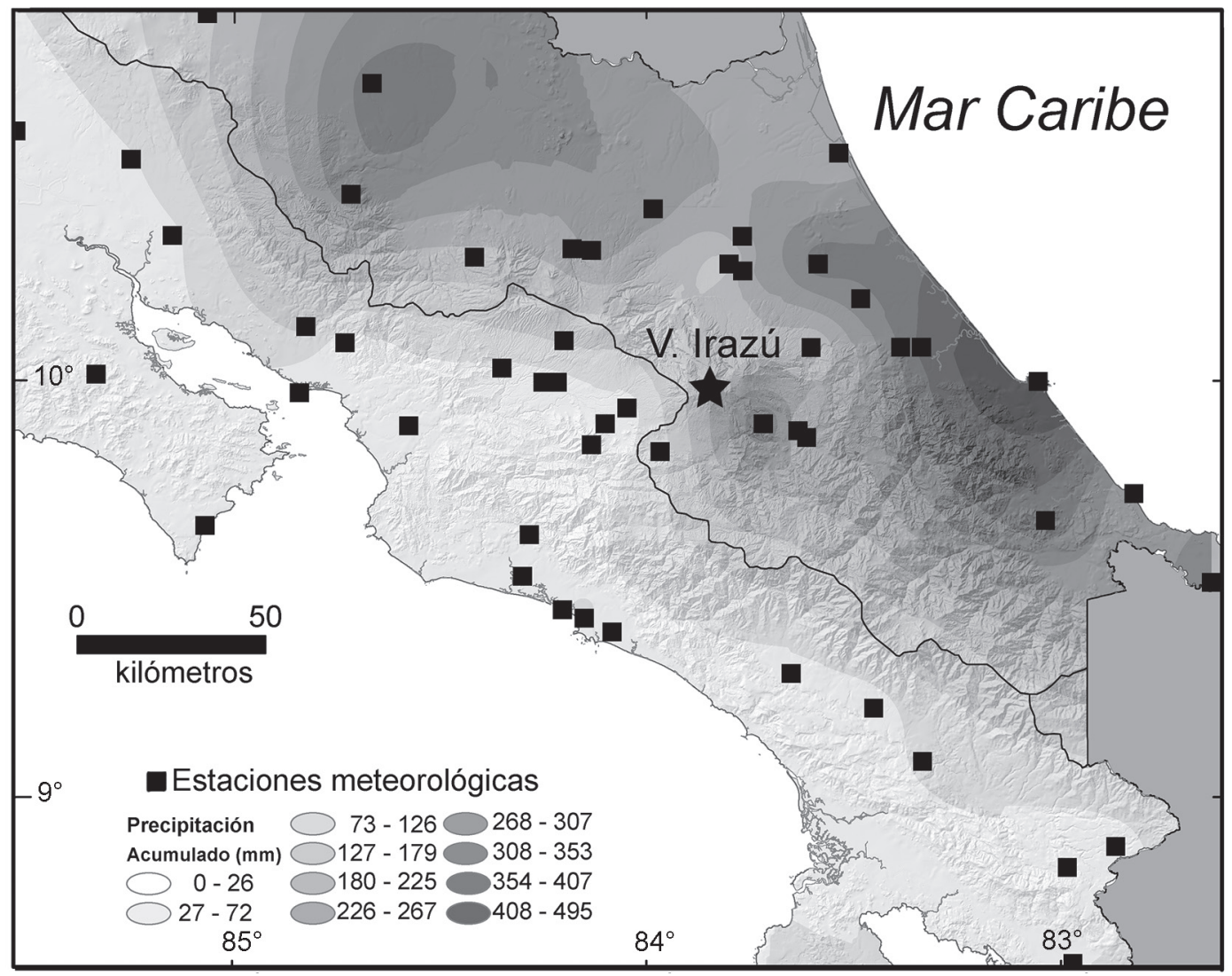

Fig. 2: Precipitación acumulada en Costa Rica durante el periodo del 3 al 9 de diciembre de 1994. Se utilizaron los datos de precipitación diaria disponibles de estaciones meteorológicas del Instituto Meteorológico Nacional (IMN), el Instituto Costarricense de Electricidad (ICE) y la Universidad de Costa Rica. Proyección y datum utilizados: WGS84.

Costa Rica. Este temporal se desarrolló a partir de cuatro factores sinópticos, según Alvarado (1994): Primero, la persistencia que mostró un máximo de vientos del noreste, de entre 40 y $70 \mathrm{~km} / \mathrm{h}$, entre superficie y el nivel de $650 \mathrm{hPa}(3700 \mathrm{~m}$ s.n.m aproximadamente). Segundo, una circulación anticiclónica en niveles bajos, que se mantuvo semiestacionaria entre los paralelos 20 y $30^{\circ} \mathrm{N}$ y que reflejó un patrón de altas presiones que predominó en superficie. Tercero, en la troposfera alta, en el nivel de $250 \mathrm{hPa}$ (10 $900 \mathrm{~m}$ s.n.m aproximadamente) se observó durante el temporal un extenso anticiclón/ dorsal y un área de aire divergente, cubriendo el territorio de Costa Rica, lo cual favoreció los movimientos ascendentes del aire desde niveles más bajos y posibilitó el desarrollo y fortalecimiento de los sistemas nubosos. Cuarto, el radiosondeo del día 7 de diciembre, previo al deslizamiento ocurrido en el volcán Irazú, mostró la presencia de una capa de aire húmedo y potencialmente inestable en prácticamente toda la troposfera. Los índices atmosféricos manifestaron condiciones convectivas suprimidas, lo que indica que la liberación de la inestabilidad potencial o convectiva se realizó gradualmente. Este es el mecanismo que explica el tipo de lluvia moderada y continua que predominó durante el temporal.

Estos factores sinópticos, en conjunto con la pronunciada orografía en la parte central y sur de la vertiente del Caribe, así como su orientación, constituyeron los factores mesoescalares que originaron el fuerte impacto del temporal en el lado oriental del país, debido a las circulaciones ascendentes (ascenso por la montaña y convergencia 
alisio-rotor) que se produjeron de la interacción del viento alisio y la orografía, lo que generó abundante nubosidad y contribuyó con la liberación de inestabilidad potencial (Alvarado, 1994). Vega (1994) también reportó que, a partir del día 18 de noviembre, la presencia de sistemas transitorios de alta presión sobre la parte sur de los Estados Unidos provocaron un incremento en el gradiente de presión meridional de presión sobre el área en la atmósfera tropical, originando vientos moderados del norte, lo que se manifestó en un acentuado aumento de lluvias en la vertiente del Caribe. El temporal de diciembre de 1994 fue inusual por cuanto no se desarrolló a partir de una vaguada de altura o un frente frío, sino por el mecanismo descrito anteriormente, el cual es anómalo en la troposfera alta (Alvarado, 1994). De acuerdo con Zárate (2013), se observaron solo 4 empujes polares en el mar Caribe durante el mes de diciembre, precedidos de 3 en el mes de noviembre, ambos meses por debajo del promedio histórico de ocurrencias observadas entre las temporadas 1975-2011 de 3,4 y 4,2, en noviembre y diciembre, respectivamente.

\section{NARRATIVA DEL EVENTO DEL 8 DE DICIEMBRE DE 1994}

\section{Descripciones y datos vertidos en documentación científico-técnica de la época}

El 8 de diciembre de 1994, a las 10:48 p.m., se reportó actividad explosiva fréatica en el volcán Irazú, la cual generó deslizamientos, lahares y una nube de ceniza que alcanzó poblaciones del Valle Central, tales como Montes de Oca, Rancho Redondo, Tres Ríos, Desamparados, Alajuelita y Aserrí (Instituto Costarricense de Electricidad [ICE], 1994; Paniagua, 1994; Fernández, et al., 1994; Barquero, et al., 1995a; Mora, Ash, Oconitrillo y Salazar, 1996). Sin embargo, en lugares ubicados al norte del volcán Irazú, tales como San Gerardo y la finca El Sitio no hubo caída de ceniza, lo cual habría sido generado por el régimen de vientos alisios que soplaron hacia el WSW (ICE, 1994; Paniagua, 1994). La ceniza, según ICE (1994), era de color gris claro, con un tenue olor azufroso, compuesta por fragmentos de rocas hidrotermalizados de tamaño arena en lugares cercanos al volcán como Rancho Redondo, y de tamaño polvo fino en los más lejanos como San José. Fernández et al. (1994) igualmente reportan que la ceniza es color gris claro, de grano fino y con bloques pre-existentes ricos en agua. ICE (1994), Barquero et al. (1995a) y Fernández et al. (1994) coinciden en que se trata de material lítico.

ICE (1994) describe que en el sitio de la explosión quedó un cráter principal del cual podía verse un pequeño escarpe a unos 2900 m s.n.m. y que estaría bastante relleno de material rocoso. En algunos informes se indicó que ese cráter habría tenido unos 60 a 80 m de diámetro (RSN, 1994a; Paniagua, 1994; Global Volcanism Program (1994c).

Otro aspecto que se rescata de la documentación de la época, es la descripción de la señal sísmica que coincidió con el evento. Se estima, según los reportes, que la energía mecánica liberada habría sido equivalente a un sismo de magnitud $\mathrm{MD}=4,4$, con base en el registro sísmico de la estación San José (SJS) de la Red Sismológica Nacional (RSN: ICE-UCR), ubicada en la Ciudad Universitaria Rodrigo Facio de la Universidad de Costa Rica en San Pedro de Montes de Oca (RSN, 1994b; ICE, 1994; Global Volcanism Program, 1994c). También se reportó el registro de eventos de baja frecuencia y tremor en una estación portátil que se instaló a partir del 10 de diciembre de 1994 cerca de la zona del cráter principal (ICE, 1994).

Asociados con el proceso se informó que se escucharon diferentes sonidos. RSN (1994b) reportó que en Coronado, pasadas las 10:00 p.m. del 8 de diciembre de 1994 se escucharon dos estruendos y después de cada uno de ellos se percibió la caída de fragmentos de roca sobre el techo de las casas. También se reportaron sonidos similares a un "jet" por varios minutos según habitantes del flanco N y NW del volcán (ICE, 1994; Fernández et al., 1994; Global Volcanism Program, 1994c).

\section{Descripciones y datos vertidos en la prensa escrita}

El impacto noticioso del evento del 8 de diciembre de 1994 en el volcán Irazú duró 9 días, entre el 9 y el 17 de diciembre, con un máximo de 
información en todos los medios de prensa el día 10 de diciembre de 1994.

Uno de los testimonios que más detalla lo ocurrido es de Carlos Jiménez, vecino de San Cayetano (a unos $10 \mathrm{~km}$ al norte del pie de la cima, al pie del volcán Irazú) quien reporta al periódico La República lo siguiente: "El jueves anterior, a las 10:30 p.m., Carlos Jiménez fue despertado por un estruendo comparable con el que hace un avión de gran tamaño cuando aterriza en el aeropuerto Juan Santamaría" (Sánchez, 1994a, p. 10A). Este ruido "se hacía cada vez más fuerte". Al salir de su casa hacia el potrero se percató que el estruendo provenía del volcán. Asimismo describe que:

al mismo tiempo que el ruido se hacía más fuerte, durante al menos 15 minutos, comenzó a notar que el suelo se movía como si estuviera parado sobre una masa viviente o una gran cafetera cuyo contenido está en ebullición. Al mismo tiempo los horcones y las latas de la cabaña rechinaban y se estremecían como por la acción de una mano gigante. Mientras eso pasaba, agregó, al pie del volcán se podía observar un resplandor rojo, el cual, cuando el sonido y la vibración llegaron a su punto máximo, dejó de existir y dio paso a la expulsión de una gran columna de humo negro, la cual, aseveró, fue de mucho mayor altura que el mismo volcán (Sánchez, 1994a, p. 10A).

Finalmente también agrega que "Pasado ese acontecimiento, la calma volvió a la zona durante unos 10 minutos, luego de los cuales volvieron el ruido como de avión que aterriza y el estremecimiento de la tierra. Esta vez, duró unos cinco minutos, pero no causó una nueva columna de humo." (Sánchez, 1994a, p. 10A).

Por otra parte, Francisco Brenes, trabajador de la zona de San Gerardo, indicó a La República que "desde el 4 de noviembre comenzó la caída pronunciada de materiales que componen la ladera norte del cráter principal del Irazú, justo sobre el sitio donde nace el río Sucio" (Sánchez, 1994b, 4A). También indicó que "ese día cayó un fragmento tan grande que su impacto en el fondo provocó que se estremecieran montañas vecinas. A partir de ese momento las caídas de material han sido constantes, lo cual, en su criterio, taponeó varias bocas, o fumarolas, por las que el volcán libera gases" (Sánchez, 1994b, 4A). Finalmente comenta que: "días antes de la explosión de la noche del jueves anterior esos escapes desaparecieron, y una vez pasada la erupción quedó un gran hoyo" (Sánchez, 1994b, 4A).

Ambos testimonios son reveladores, dado que sugieren: 1) el hecho de que ocurrieran al menos dos aludes importantes luego del desprendimiento, 2) que hubo una columna alta de material que se levantó luego del primer evento, 3) que habría eventualmente intervenido una fuerte desgasificación debido al fuerte "sonido de jet" escuchado que se diferencia de la trepidación generada por el alud y que es descrita de manera diferente, 4) evidencia de que ya desde antes habían desprendimientos que habrían generado un bloqueo en el campo de fumarolas, dado que incluso precisa que estos "escapes desaparecieron" antes de la "erupción".

\section{GEOMORFOLOGÍA}

\section{Geomorfología del área cuspidal del volcán Irazú}

El volcán Irazú es un volcán andesítico con forma de escudo (o estratovolcán complejo amplio) cuyo volumen total ha sido calculado por Carr et al. (2007) y Gross, Van Wyk de Vries, Petrinovic, Eullades y Alvarado (2009), quienes, con diferentes metodologías y según la cota mínima utilizada, llegaron a valores de $130 \mathrm{~km}^{3}$ y $319 \mathrm{~km}^{3}$ respectivamente. Aunque existen diferencias significativas entre estos resultados, ambos valores son superiores al promedio del resto de estratovolcanes del arco volcánico de América Central, con excepción de los otros volcanes de la Cordillera Volcánica Central de Costa Rica. Algunos ejemplos de mapas geomorfológicos anteriores también se muestran en Soto (1994) y Alvarado (2009).

Las tres cuartas partes de las laderas del volcán Irazú se ubican en la vertiente Caribe, en donde las precipitaciones anuales superan los 4000 $\mathrm{mm}$. En consecuencia, tanto el flanco norte como el noreste se encuentran más disectados por los procesos de meteorización y erosión producto de la intensa humedad y lluvia. Asimismo, es en este sector donde también son más frecuentes los deslizamientos (Fig. 3).

En la cima se encuentra el cráter principal, que estuvo activo entre 1962 y 1965 . Tiene una forma 
general circular de unos $1000 \mathrm{~m}$ de diámetro y una profundidad de $250 \mathrm{~m}$. En sus paredes internas se pueden apreciar flujos de lava que además presentan pendientes con ángulos casi verticales en algunos sectores. Hasta el año 2010, hubo un lago cratérico de poca profundidad (entre 14 y $20 \mathrm{~m}$ ) con temperaturas entre 30 y $12^{\circ} \mathrm{C}$. $\mathrm{Al}$ desaparecer este cuerpo de agua de origen meteórico, hoy son visibles morfologías como depósitos de deslizamientos, deltas y coluvios. Además, es posible observar un dique ubicado en el sector noreste del interior de este cráter, donde por muchos años existieron fumarolas. En este mismo sector del cráter, pero en la pared externa, se ubica el deslizamiento que tuvo lugar en 1994 y que se describe en este trabajo. Con el nuevo MED en este lugar, se pueden apreciar alineamientos que se interpretan como fallas y que concuerdan con las estructuras y planos descritos por Ulloa et al. (2014), cerca de donde se encuentra la cueva Los Minerales. Ese sector actualmente presenta pendientes superiores a $55^{\circ}$, aunque hay una zona plana hacia el noroeste. Los drenajes en esta zona son profundos y cambian bruscamente de dirección debido a bloques u obstáculos que quedaron después del evento del 1994.

Al este del cráter principal, se encuentra otra depresión conocida como cráter Diego de la Haya, de forma oblonga, con una profundidad menor que el principal $(80 \mathrm{~m})$ debido a la acumulación de ceniza del último periodo eruptivo. En sus bordes se observan algunos abanicos y depósitos coluviales. En algunas ocasiones se puede formar un pequeño lago efímero en su parte central, lo cual se da principalmente en la época lluviosa y persiste solo por unas semanas.

Hacia el sur de los cráteres principal y Diego de la Haya se ubica Playa Hermosa, considerada una terraza volcánica donde se encuentran depósitos de corrientes piroclásticas de baja densidad acumulados en los bordes de una depresión más grande que se ha interpretado como un borde de caldera o un cráter mayor. En este sector plano y extenso es frecuente la formación de un lago efímero durante la época lluviosa. Al este de los cráteres hay un cono piroclástico, conocido como La Laguna, que presenta coladas de lava y depósitos piroclásticos, algunos de ellos con texturas que muestran mingling de magmas (Alvarado,
1993). Otro pequeño cono piroclástico destruido se ubica al este de esta estructura. Mientras que hacia el sur se ubica otro cono algo erosionado, en el que sus principales productos fueron coladas de lava y piroclastos subordinados.

Unos dos kilómetros hacia el suroeste del cráter principal se ubica un deslizamiento de grandes proporciones y que representa un peligro para el sector donde se ubican las torres de radio y televisión de muchas emisoras y canales del país. Por esta razón, se le conoce como Deslizamiento las Torres (Mora y Pirulli, 2017). En este sector las pendientes son superiores a $55^{\circ}$ y los materiales presentes corresponden con piroclastos y lavas afectadas por alteración hidrotermal (Fig. 3).

\section{Restitución fotogramétrica del deslizamiento de 1994 a partir de las fotografías aéreas históricas}

Para generar el MED del deslizamiento de 1994 en el volcán Irazú, se utilizaron las fotografías aéreas del IGN, obtenidas el 20 de diciembre de 1994 a escala 1:10 000. Estas se encuentran en formato de $23 \mathrm{~cm} \times 23 \mathrm{~cm}$, cuentan con cuatro marcas fiduciales (cada una en la parte central en los extremos de la fotografía). El recubrimiento o traslape lateral entre los pares de fotografías varía entre el 64 y $88 \%$, con un promedio de $80 \%$, lo cual es suficiente para garantizar que se pueda proceder con la restitución. Todas las fotografías fueron tomadas con una distancia focal de $152,44 \mathrm{~mm}$ y a una altura de vuelo de $4543 \mathrm{~m}$ s.n.m. Estas fotografías fueron digitalizadas con un escáner fotogramétrico que permitió obtener imágenes de 11834 x 11942 pixeles a una resolución de 1200 ppp. El resultado obtenido fue de buena calidad gracias a que se conservan en muy buen estado y fueron tomadas con una cámara fotogramétrica analógica adecuada, lo que ayudó en gran medida a obtener imágenes con contrastes y nitidez aceptables.

A pesar de los aspectos favorables indicados anteriormente, también hubo varias limitaciones para efectuar la restitución fotogramétrica. En primera instancia, el IGN no cuenta con el certificado de calibración de la cámara utilizada para la adquisición de las fotos aéreas. En consecuencia, no se 


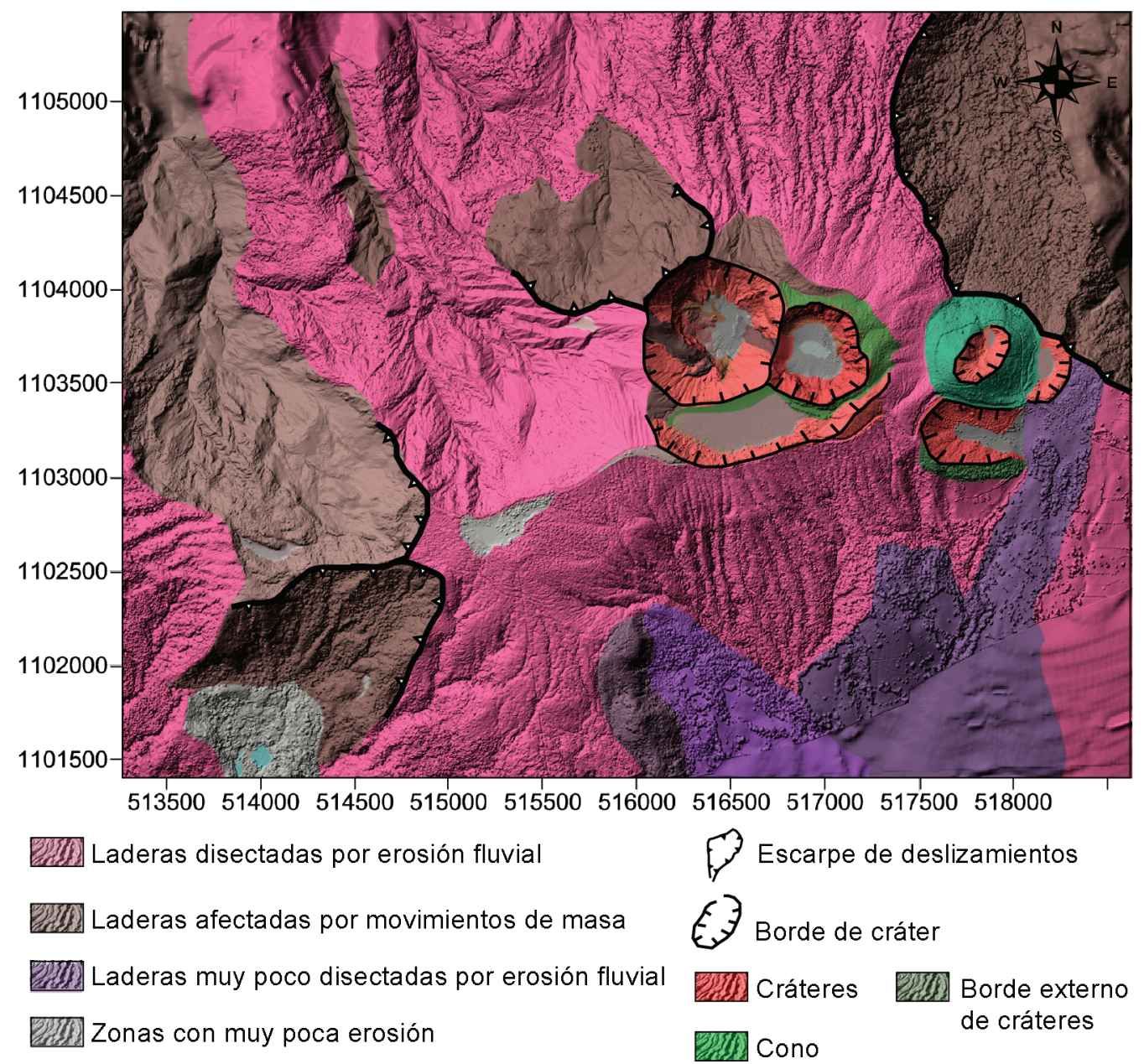

Fig. 3: Mapa geomorfológico del área cuspidal del volcán Irazú. La base topográfica está constituida por el modelo de elevación digital generado por AERODIVA S.A. (2015).

conocen las coordenadas de las marcas fiduciales y del punto principal en el sistema coordenado de la cámara utilizada, ni tampoco los coeficientes de distorsión radial de la lente. Esto es un problema que incide en el proceso de orientación interna y es común en los trabajos de restitución fotogramétrica a partir de fotografías aéreas históricas (e.g. Chandler, 1984; Walstra, Chandler, Dixon y Dijkstra, 2004; Zanutta, et al., 2006; Walstra, Dixon y Chandler, 2007; Escarcena Cardenal, et al., 2008; Mikrut, 2008; Vales et al., 2010). Segundo, no se pudo contar con puntos de control debidamente georreferenciados debido a la dificultad de acceso al área del deslizamiento, la cual es una zona de topografía muy abrupta, en gran parte con laderas inestables y alrededores con gran cobertura boscosa. Esto último incide directamente en el proceso de orientación externa. $\mathrm{La}$ corrección por la curvatura terrestre no fue necesaria por la escala de las fotografías.

Debido a estas limitaciones, fue necesario adoptar un procedimiento no convencional con el fin de poder generar el MED de las fotografías aéreas históricas, el cual conduce a un resultado menos preciso del que se habría obtenido si se siguiera el procedimiento de restitución fotogramétrico riguroso bajo condiciones óptimas. Sin embargo, esta aproximación es suficiente para 
la caracterización geológica del proceso desde la óptica del análisis de la amenaza volcánica por procesos gravitacionales en el volcán Irazú.

Se efectuaron dos procesos de restitución fotogramétrica utilizando dos combinaciones de fotografías aéreas: una combinación de cuatro fotos y otra de seis fotos, con el fin de establecer si el número de fotos utilizado incidía en la resolución del MED final. A continuación se describe cada proceso de la restitución.

\section{Orientación interna}

El proceso de orientación interna permite reconstruir el sistema de referencia de la fotografía y establecer los parámetros de transformación entre el sistema de coordenadas de la cámara y la fotografía. De esta forma es posible pasar del sistema de coordenadas de píxel de la imagen u otro sistema de medición de coordenadas de la imagen al sistema de coordenadas espaciales de ella (INTERGRAPH, 2013).

Al no contar con el certificado de calibración de la cámara, las coordenadas del punto principal y de las marcas fiduciales en el sistema coordenado de la cámara así como los parámetros de distorsión de la lente se desconocen. En consecuencia, se ignora el efecto de la distorsión del objetivo, la deformación de la película fotogramétrica y la no alineación del punto principal con su posición teórica y, por lo tanto, únicamente se utiliza la distancia focal indicada en las fotografías y las coordenadas de las marcas fiduciales obtenidas en el sistema coordenado de ellas (Zanutta et al., 2006). Estas coordenadas se obtienen midiendo la distancia a la que encuentra cada marca fiducial con respecto a la intersección de las rectas que unen las marcas fiduciales laterales opuestas. Estos ejes se alinean con el sistema coordenado del programa para efectuar las medidas. Al no contar con los sistemas de coordenadas instrumentales para cada fotografía, es necesario aproximar uno a partir del sistema coordenado de las fotografías que permita una calidad de la transformación bidimensional aceptable. Esto significa que esa transformación arroje valores de error cuadrático medio (RMSE) menores a un pixel (Quirós, 2014).

En el conjunto de 4 fotografías las mediciones de coordenadas de las marcas fiduciales fueron muy similares para tres de ellas, por lo que se promediaron y se asignó este promedio a la fotografía restante que presentó mayor variación con respecto a las demás. En el conjunto de 6 fotografías, el promedio no funcionó de la misma manera que con el conjunto de 4 fotos y solo se asignó a dos fotografías (Cuadro 1).

\section{Orientación externa: puntos de control, am- arre y verificación}

El proceso de orientación externa define la posición y la orientación angular asociada con una fotografía y requiere de los siguientes puntos de referencia: 1) Puntos de control (GCP o "ground control point"), 2) puntos de amarre ("tie points") y 3) puntos de verificación (“check points"). Los puntos de amarre ("tie points") son utilizados para mejorar el ajuste en el proceso la aerotriangulación y los puntos de verificación permiten comparar las coordenadas del punto con el modelo generado para evaluar la calidad del producto (Fig. 4).

Los puntos de control y los puntos de verificación son elementos de los cuales se conocen

Cuadro 1

Raíz cuadrada del error cuadrático medio (RMSE) de la orientación interna.

\begin{tabular}{ccc}
\hline Combinación & Imagen & RMSE (pixeles) \\
\hline \multirow{4}{*}{4 fotografías } & 52729 & 0,97 \\
& 52730 & 0,61 \\
& 52731 & 1,17 \\
& 52732 & 0,18 \\
\hline \multirow{6}{*}{6 fotografías } & 52729 & 0,15 \\
& $52730\left(^{*}\right)$ & 0,61 \\
& 52731 & 0,13 \\
& $52732\left(^{*}\right)$ & 0,17 \\
& 52757 & 0,10 \\
\hline
\end{tabular}

(*) Fotografías en las cuales se utilizó el valor promedio. 


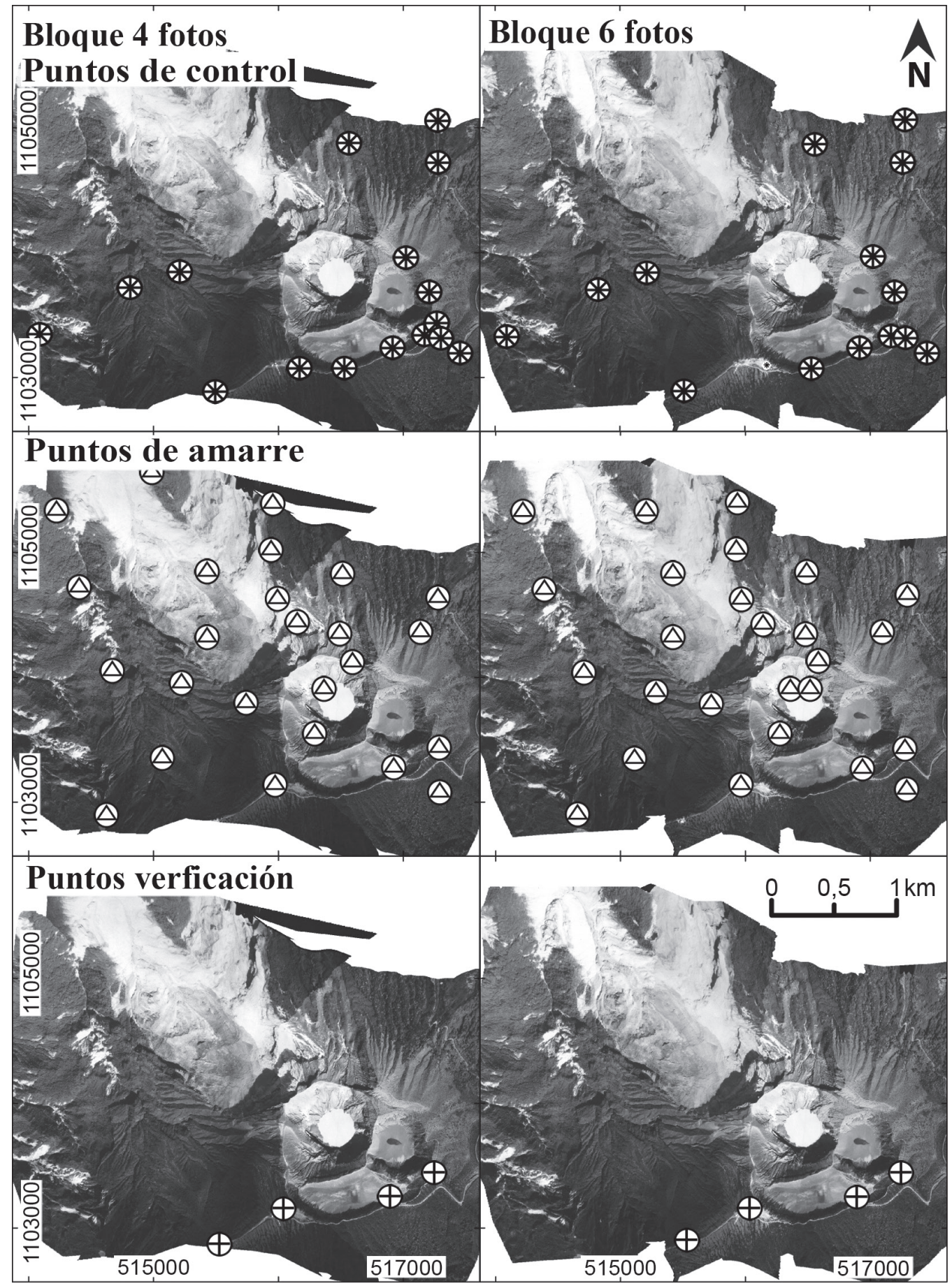

Fig. 4: Ubicación de los puntos de control, amarre y verificación, utilizados en el proceso de la orientación externa de las fotografías aéreas de 1994, para los bloques de 4 y 6 fotos. Fotografías aéreas suministradas por el Instituto Geográfico Nacional (IGN). Proyección CRTM05 y datum WGS84. 
las coordenadas en el campo, por lo que deben ser puntos georreferenciados, que a su vez sean identificables en las fotografías aéreas. Sin embargo, por las razones explicadas anteriormente, no fue posible obtenerlos. Alternativamente, se utilizó el servicio WMS (Web Map Service) de ortofotos a escala 1:5000 y 1:1000 del Servicio Nacional de Información Territorial (SNIT), que pertenece al Programa de Regularización de Catastro y Registro de Costa Rica. Este servicio fue utilizado como referencia espacial para obtener la latitud y longitud de los elementos reconocibles, tanto en las fotos aéreas como en las ortofotos del SNIT, como por ejemplo: obras civiles, elementos en la red vial y de drenaje así como rasgos topográficos, entre otros. La principal limitación se deriva de los cambios temporales en la cobertura vegetal y la morfología del terreno debido a los procesos de erosión, ya que las imágenes del SNIT fueron tomadas en el 2005 y el 2007. Pese a ello, se procuró obtener puntos que tuvieran una distribución espacial amplia.

La incertidumbre en la localización (latitud y longitud) de los puntos de control se puede estimar a partir del tamaño de celda a la máxima escala de visualización que permite el SNIT, el cual se obtiene a partir de la relación: Tamaño de celda $=$ Escala de visualización $\times(0.0254 / 96)($ ESRI, 2016). Considerando que la escala de máximo acercamiento fue de 1:1,334, el tamaño de celda asociado es de $0,36 \mathrm{~m}$. Por consiguiente, la incertidumbre en las coordenadas sería de al menos la mitad de la celda, es decir, $\pm 0,18 \mathrm{~m}$, tanto en la longitud como en la latitud. A esta incertidumbre se adiciona el tamaño de los elementos de los puntos de control que pueden estar conformados por varias celdas, lo cual no se cuantificó.

Para obtener las cotas de altitud de los puntos de control, se utilizó un MED generado a partir de la cartografía oficial a escala 1:50 000 del IGN con curvas de nivel cada $20 \mathrm{~m}$. Asimismo, con el fin de tener un valor de incertidumbre aproximado asociado con la altitud, se utilizaron 6 puntos obtenidos por medio de un GPS geodésico que forman parte de una campaña de medición gravimétrica que se efectuó cerca de la cima del volcán Irazú en el año 2015 (Fig. 5). Estos puntos no pueden utilizarse como puntos de control ya que no corresponden con elementos identificables en las fotografías aéreas, pero sí son útiles como valores de referencia para comparar los valores de altitud con aquellos indicados en el MED de la cartografía oficial a escala 1:50 000. Los diferenciales de estos valores se promediaron y se obtuvo un resultado de 9,88 $\mathrm{m}$ que ha sido tomado como incertidumbre aproximada en las cotas de altitud.

Los puntos de amarre ("tie points") son elementos comunes de las fotografías ubicadas en las zonas de traslape y no se conocen sus coordenadas de terreno. Generalmente se seleccionan de manera automática con base en un algoritmo basado en los contrastes de las fotografías, sin embargo el resultado no fue satisfactorio. Por esta razón, fueron asignados manualmente, mediante una selección de puntos de buena calidad que permitiera obtener un RMSE aceptable para el producto deseado (Fig. 4).

\section{Aerotriangulación}

El proceso se llevó a cabo con un mínimo de 4 puntos de control por fotografía y un máximo variable (Cuadro 2). Los puntos de imagen son los puntos de control, verificación y amarre ubicados en cada imagen (fotografía en digital) obtenidos a partir del SNIT. El proceso de restitución opera tanto para el conjunto de fotos (imágenes) como para cada una de ellas (foto/imagen). Esto significa que se obtiene una estimación de coordenadas para todos los puntos por conjunto y por separado. $\mathrm{La}$ diferencia entre ellas es el RMSE por cada punto de foto/imagen. Este error se expresa como el valor promedio de todos los errores individuales de todos los puntos de foto/imagen (control, verificación y amarre) y se indica en el cuadro 3 como X Imagen y Y Imagen. Se observa que para el bloque de 4 fotos, esos errores son menores que 1 en contraste con el bloque de 6 fotos que son bastante altos. Esto significa que las fotos/imágenes del conjunto de 6 fotos presentan una mayor distorsión, dado 


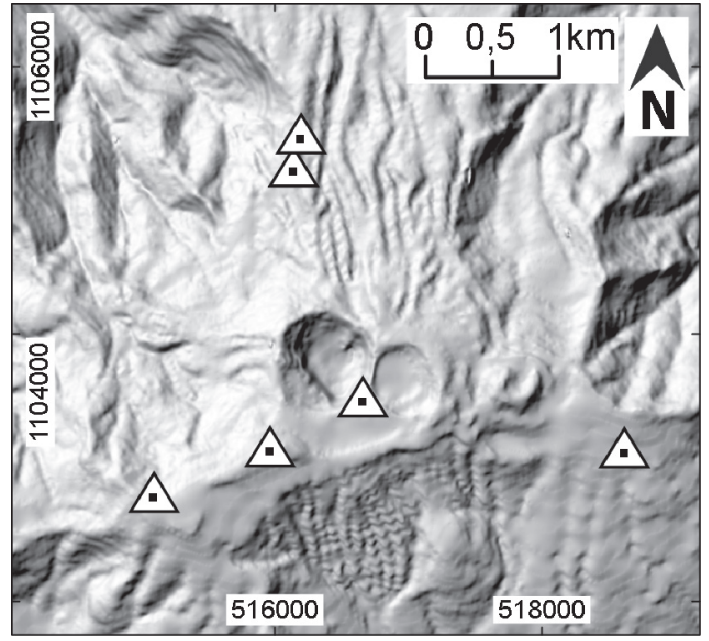

Fig. 5: Ubicación de los puntos obtenidos mediante GPS geodésico que forman parte de una campaña de medición gravimétrica que se efectuó cerca de la cima del volcán Irazú en el año 2015. Proyección CRTM05 y datum WGS84.

que involucra dos líneas de vuelo perpendiculares, lo que torna más complejo el ajuste. Finalmente, para ambos bloques de fotografías se obtuvo valores de RMSE (en metros) menores que 1 en los puntos de control y verificación, tanto en longitud como en latitud (Cuadro 3).

En cuanto al error en el ajuste en la altitud ( $Z$ Terreno) del cuadro 3 , tenemos que para ambos conjuntos es superior a los $30 \mathrm{~m}$. Esto es consistente con la incertidumbre estimada para la altitud de los puntos de control, que es del orden de 9,88 $\mathrm{m}$, y a lo que se adicionan las limitaciones metodológicas y los cambios de la geomorfología por erosión durante el tiempo. Otro aspecto importante, es que el modelo del cual se obtuvieron las cotas de altitud fue generado a partir de curvas de nivel cada 20 metros a escala 1: 50000 , mientras que las fotografías aéreas son a escala 1:10 000; este cambio de escala afecta el producto generado y limita la precisión en el ajuste en la coordenada Z.

En general, vemos que el RMSE global obtenido para el conjunto de 6 fotografías es muy alto (Cuadro 3), consecuencia del método poco ortodoxo para generar la restitución, ya que implicó la
Cuadro 2

Número máximo de puntos de control utilizado en cada fotografía

\begin{tabular}{ccc}
\hline Bloque & $\begin{array}{c}\text { Número de } \\
\text { fotografía }\end{array}$ & $\begin{array}{c}\text { Número máximo de } \\
\text { puntos de control }\end{array}$ \\
\hline \multirow{3}{*}{4 fotos } & 52729 & 12 \\
& 52730 & 14 \\
& 52731 & 7 \\
52732 & 4 \\
\hline 6 fotos & 52729 & 12 \\
& 52730 & 13 \\
& 52731 & 5 \\
& 52732 & 4 \\
& 52757 & 9 \\
& 52758 & 12 \\
\hline
\end{tabular}

mezcla de dos líneas de vuelo, de tal manera que los puntos en común de una imagen con otra ya no se ubican solamente en dos imágenes (zonas de traslape), sino que existen puntos hasta en cuatro imágenes, lo que también hace que el ajuste sea más complejo. A esto se suman las limitaciones metodológicas explicadas supra, tales como: no contar con las coordenadas del punto principal, distancia focal calibrada y los coeficientes de distorsión radial (certificado de calibración), lo que no permite efectuar las correcciones debidas a la distorsión radial y tangencial provocadas por la lente de la cámara (Brown, 1966).

El resultado general de la restitución fotogramétrica, expresados en la posición del centro de proyección en el momento en que fueron tomadas las fotografías, y los ángulos de rotación OMEGA para el eje "X", PHI par el eje "Y" y KAPPA para el "Z", se muestran en el cuadro 4. Los ángulos de rotación son positivos en el sentido contrario a las manecillas del reloj (INTERGRAPH, 2013). Para OMEGA y PHI los valores son bajos y dentro de lo esperable, en tanto que los valores altos de KAPPA para las fotografías 52757 y 52758 del conjunto de 6 fotos son bastante altos debido a que pertenecen a otra línea de vuelo. 
Cuadro 3

Resultado general de las aerotriangulaciones.

\begin{tabular}{cccc}
\hline Bloque & & RMSE Puntos de control & RMSE Puntos de verificación \\
\hline \multirow{3}{*}{4 fotos } & X Terreno (metros) & 0,1858 & 0,1634 \\
& Y Terreno (metros) & 0,2365 & 0,2074 \\
& Z Terreno (metros) & 34,8244 & 26,4315 \\
& X Imagen (píxeles) & 0,4148 & 0,3350 \\
& Y Imagen (píxeles) & 0,6834 & 0,4736 \\
\hline RMSE Global: 0,9427 & & 0,2006 \\
\hline \multirow{2}{*}{6 fotos } & X Terreno (metros) & 0,3175 & 0,5842 \\
& Y Terreno (metros) & 0,5769 & 34,2319 \\
Z Terreno (metros) & 51,1100 & 6,3032 \\
X Imagen (píxeles) & 5,6112 & 7,2530 \\
\hline
\end{tabular}

Estimación del volumen de material deslizado el 8 de dicie mbre de 1994

El modelo de elevación digital obtenido a partir de la restitución fotogramétrica de las fotos aéreas históricas fue filtrado levemente para efectos de eliminar la alta rugosidad y con ello facilitar la estimación del volumen del material deslizado. Se utilizó un filtro de media de $3 \times 3$ píxeles (Müeller y Hoffer, 1989) que fue aplicado 3 veces hasta lograr un suavizado aceptable (Fig. 6).

El área deslizada fue delimitada con base en un análisis geomorfológico de las fotografías aéreas, la cual se estima en $2,7 \times 10^{5} \mathrm{~m}^{2}$ (Fig. 7). Por otra parte, la estimación del volumen deslizado se efectuó por sustracción, celda por celda, de los

Cuadro 4

Precisión de los puntos de control por imagen/foto y parámetros de la orientación externa.

\begin{tabular}{cccccccccc}
\hline \multirow{2}{*}{ Bloque } & \multirow{2}{*}{ Imagen } & \multicolumn{2}{c}{$\begin{array}{c}\text { RMSE puntos de } \\
\text { control (pixel) }\end{array}$} & \multicolumn{2}{c}{$\begin{array}{c}\text { Posición del centro de perspectiva } \\
\text { (coordenadas CRTM05) }\end{array}$} & \multicolumn{2}{c}{$\begin{array}{c}\text { Elementos rotacionales de la orient- } \\
\text { ación externa (grados) }\end{array}$} \\
\cline { 3 - 11 } & & $\mathrm{X}$ & $\mathrm{Y}$ & $\mathrm{X}$ & $\mathrm{Y}$ & $\mathrm{Z}$ & $\mathrm{OMEGA}$ & $\mathrm{PHI}$ & KAPPA \\
\hline \multirow{4}{*}{4 fotos } & 52729 & 0,307 & 0,705 & 517182 & 1103900 & 4744 & $-3,9402$ & $-0,6986$ & $-5,7194$ \\
& 52730 & 0,401 & 0,693 & 516440 & 1103975 & 4768 & $-4,5991$ & $-0,9953$ & $-5,5499$ \\
& 52731 & 0,490 & 0,772 & 515554 & 1104069 & 4782 & $-5,4516$ & $-1,1952$ & $-6,1525$ \\
& 52732 & 0,570 & 0,506 & 514652 & 1104175 & 4792 & $-3,9288$ & $-358,9113$ & $-6,3246$ \\
\hline \multirow{3}{*}{6 fotos } & 52729 & 3,377 & 3,350 & 517181 & 1103912 & 4738 & $-4,4199$ & 0,7380 & $-5,7185$ \\
& 52730 & 7,904 & 4,413 & 516435 & 1103982 & 4760 & $-4,9654$ & 0,9285 & $-5,4328$ \\
& 52731 & 5,830 & 8,983 & 515580 & 1104072 & 4777 & $-5,6904$ & 1,1453 & $-5,9132$ \\
& 52732 & 2,688 & 4,861 & 514693 & 1104180 & 4803 & $-4,2742$ & 2,3106 & $-5,9878$ \\
& 52757 & 5,502 & 6,352 & 515876 & 1103954 & 4784 & $-0,1928$ & $-1,2458$ & 28,8590 \\
& 52758 & 5,093 & 6,223 & 516243 & 1103262 & 4808 & $-2,0281$ & 1,3307 & 29,4969 \\
\hline
\end{tabular}




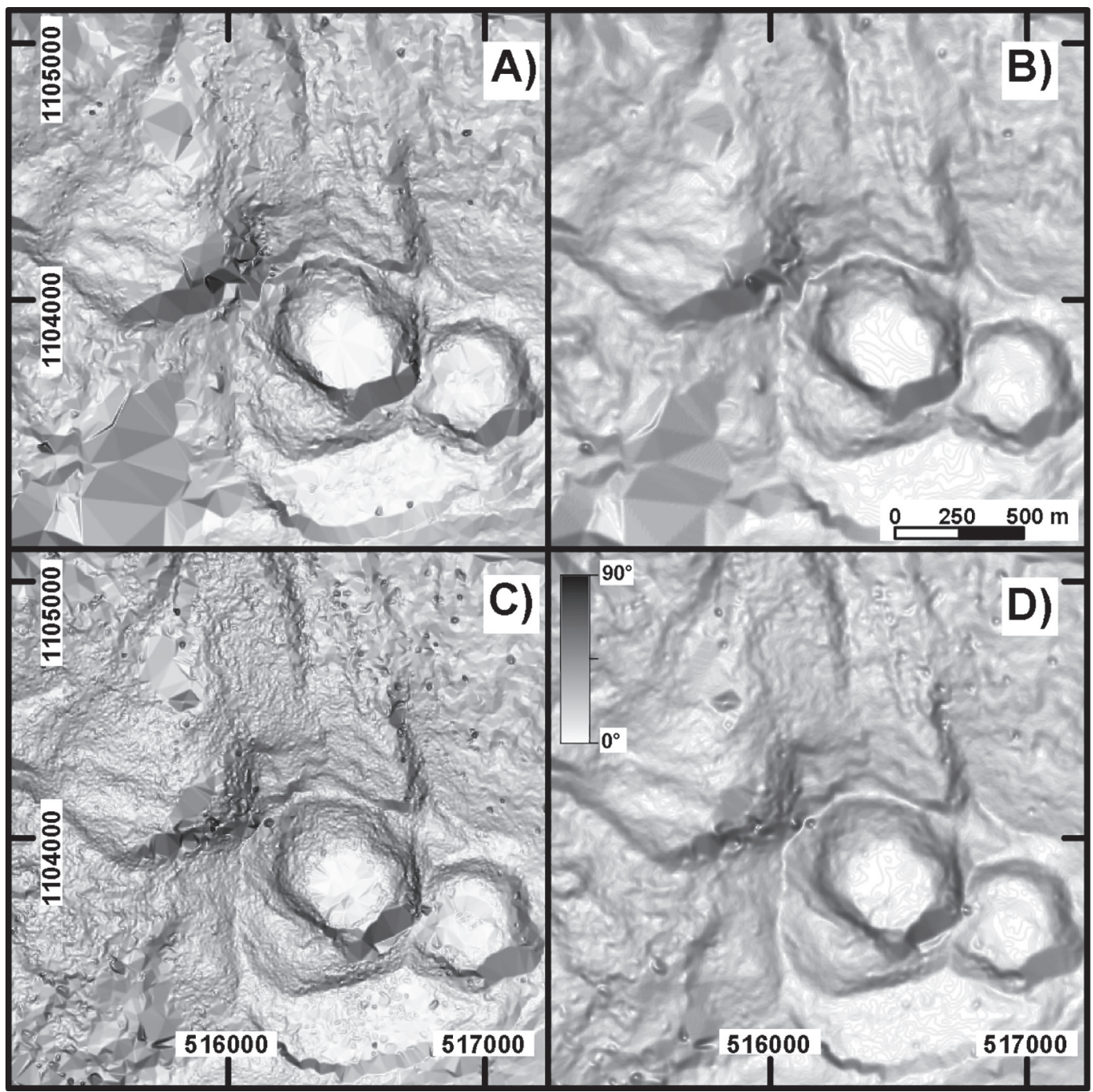

Fig. 6: Productos finales de la restitución fotogramétrica a partir de los conjuntos de 4 fotografías (A y B) y 6 fotos (C y D). Se muestran los modelos de pendientes btenidos sin filtrar (izquierda) y filtrados (derecha). Proyección CRTM05 y datum WGS84.

valores de altura obtenidos de los MED de referencia (1:50 000) y de la restitución fotogramétrica, multiplicado por el área $\left(25 \mathrm{~m}^{2}\right)$. El volumen total es simplemente la sumatoria del estimado en cada una de las celdas. Los resultados obtenidos se muestran en la figura 8 y el cuadro 5 . Este tamaño de celda es el mismo con el que se generó el MED de la cartografía oficial a escala 1:50 000 , de tal manera que los tres modelos tienen la misma resolución, lo que nos permite hacer comparaciones celda por celda entre los tres modelos.

\section{Estimación del error en el cálculo del volumen deslizado}

Para aproximar el error asociado en el cálculo del volumen por celda, se derivó parcialmente 


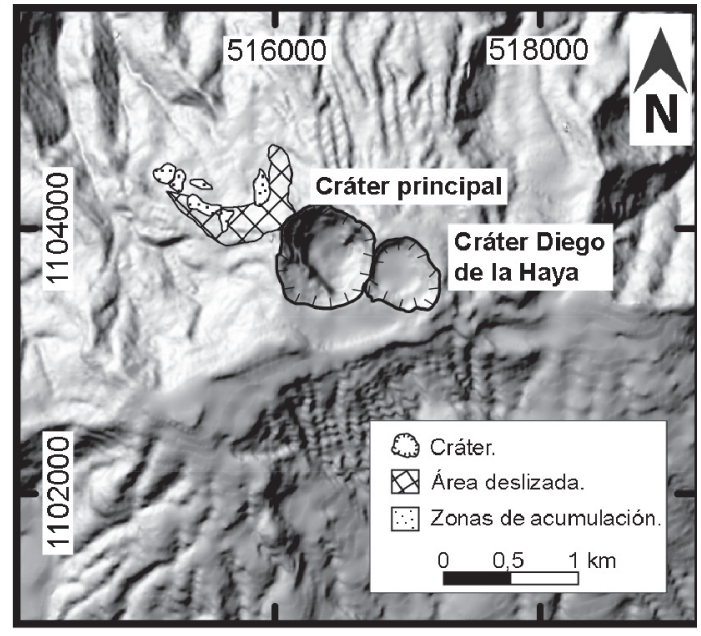

Fig. 7: Área deslizada obtenida a partir del análisis geomorfológico, y proyectada sobre el modelo de elevación digital obtenido por la restitución fotogramétrica. Proyección CRTM05 y datum WGS84.

la fórmula del volumen con respecto a la altura considerando el área como una constante, de manera que el error es el mismo en todas las celdas y resulta de multiplicar el área de la celda por la incertidumbre asociada al cambio de altura en la misma celda. Para obtener la incertidumbre en el cambio de altura, primero se determinó la incertidumbre de los modelos generados. Para ello se utilizó el mismo método aplicado para la incertidumbre en la altitud de los puntos de control, a partir de 3 puntos geodésicos.

Como se mencionó anteriormente, para los puntos de control de campo se obtuvo una incertidumbre de $\pm 10 \mathrm{~m}$. Esta incertidumbre se asume como la incertidumbre ligada al MED 1:50 000. Para el modelo a partir del conjunto de 4 fotos se obtuvo una incertidumbre de $\pm 21 \mathrm{~m}$, en tanto que para el conjunto de 6 fotos se obtuvo una incertidumbre de $\pm 19 \mathrm{~m}$.

El cambio de altura por celda fue obtenido mediante una resta de los modelos generados con respecto al MED 1:50 000, por lo que la incertidumbre de ambos modelos utilizados en la operación matemática se propaga hacia el resultado final, de manera que las incertidumbres de ambos modelos se suman, lo que da como resultado una
Cuadro 5

Resultados del cálculo de volúmenes por bloque de fotos

\begin{tabular}{ccc}
\hline Resultados obtenidos $\left(\mathrm{m}^{3}\right)$ & $\begin{array}{c}\text { Modelo de 4 } \\
\text { fotos }\end{array}$ & $\begin{array}{c}\text { Modelo de 6 } \\
\text { fotos }\end{array}$ \\
\hline Volumen mínimo por celda & 0,31 & 0,95 \\
Volumen máximo por celda & 6361 & 5309 \\
Volumen promedio por celda & 2038 & 2113 \\
Volumen total estimado & $21 \times 10^{6}$ & $22 \times 10^{6}$ \\
\hline
\end{tabular}

incertidumbre en el cambio de altura de $\pm 31 \mathrm{~m}$ para el modelo del bloque de 4 fotos $\mathrm{y} \pm 29 \mathrm{~m}$ para el modelo de 6 fotos.

En el cuadro 6 se muestra el resumen de las estimaciones realizadas para finalmente obtener el Error Relativo Porcentual (ERP) del volumen total estimado, que corresponde con un 38\% para el cálculo basado en el modelo del bloque de 4 fotos y $34 \%$ con el de 6 fotos. Otro dato importante es la distribución espacial del ERP por celda, el cual nos indica los sectores del área afectada en las que las estimaciones de volumen pierden confiabilidad debido a que el cambio de altura se encuentra bajo el umbral del valor de incertidumbre. Esta información se muestra en la figura 8, en la que se observa cómo hacia los extremos del deslizamiento aumenta ERP por celda, inclusive superior al $100 \%$, debido a que en esos sectores el cambio de altura es menor a la incertidumbre.

Finalmente, estos datos reflejan el efecto de las limitaciones con las que se trabajó, sin embargo para la aplicación final de esta información se considera aceptable por tratarse de un evento histórico, ya que brinda información de un proceso gravitacional que afectó el macizo del volcán Irazú y del que no se tenía información del volumen desplazado en este evento.

\section{DISCUSIÓN}

La literatura científica que trata sobre el proceso ocurrido la noche del 8 de diciembre de 1994 en el flanco N del volcán Irazú no es exhaustiva en cuanto al detalle de lo sucedido ni 


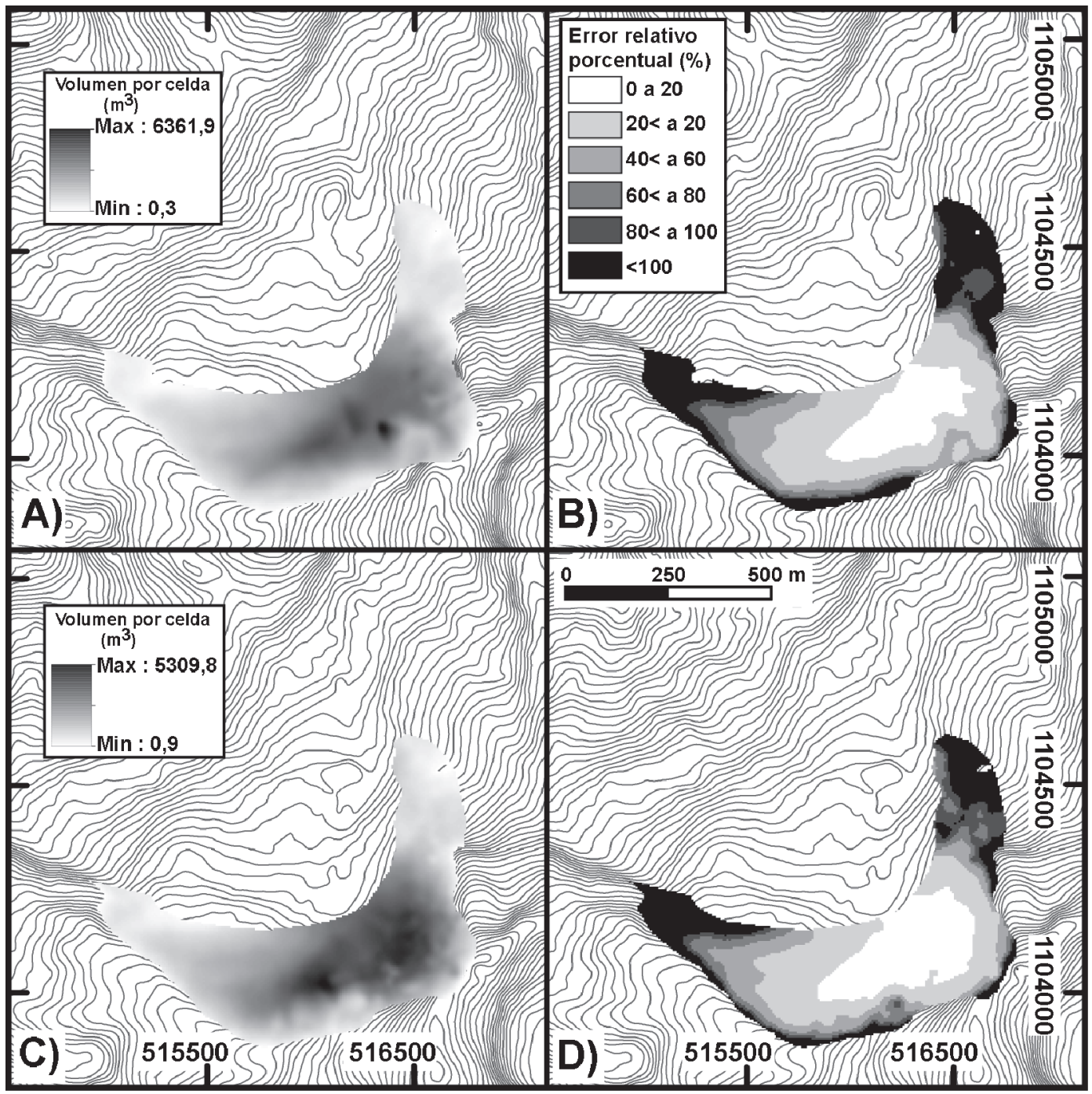

Fig. 8: Estimaciones de volumen (izquierda) y el error relativo (derecha, la escala es la misma para B y D), ambos por celdas, para los conjuntos de 4 fotografías (arriba) y 6 fotografías (abajo). Proyección CRTM05 y datum WGS84.

las características del evento. En consecuencia, es poco contundente en cuanto a la determinación del origen del proceso, por lo tanto, de alguna manera el evento pasó a la historia del volcán Irazú como una erupción freática, sin evidencias concretas que sustentaran dicha interpretación definitiva.

Sin duda alguna, también en aquella época, varios aspectos resultaron desfavorables para generar un análisis técnicamente más sustentado del proceso. Entre los más importantes están: 1) El difícil acceso al lugar de los hechos, no solo por lo abrupto del terreno, sino también por posibilidad de que pudiese ocurrir un evento similar, 2) el hecho de que el evento ocurriera durante la noche y en condiciones meteorológicas desfavorables que no permitieron hacer observaciones sino hasta dos días después, 3) el poco desarrollo tecnológico que privó de contar con mejores datos que permitieran 
Cuadro 6

Estimación de los errores en el cálculo del volumen

\begin{tabular}{ccccccc}
\hline Bloque & $\begin{array}{c}\text { Incertidumbre } \\
\text { del bloque }(\mathrm{m})\end{array}$ & $\begin{array}{c}\text { Incertidumbre en } \\
\text { cambio de altura } \\
\text { por celda }(\mathrm{m})\end{array}$ & $\begin{array}{c}\text { Error por celda } \\
\left(\mathrm{m}^{3}\right)\end{array}$ & $\begin{array}{c}\text { Total de } \\
\text { celdas }\end{array}$ & $\begin{array}{c}\text { Error del volu- } \\
\text { men total }\left(\mathrm{m}^{3}\right)\end{array}$ & $\begin{array}{c}\text { Error relativo } \\
\text { porcentual total }(\%)\end{array}$ \\
\hline 4 fotos & \pm 21 & \pm 31 & \pm 780 & 10569 & $\pm 8,2 \times 10^{6}$ & 38 \\
6 fotos & \pm 19 & \pm 29 & \pm 719 & 10556 & $\pm 7,6 \times 10^{6}$ & 34 \\
\hline
\end{tabular}

documentar adecuadamente el evento, 4) el conocimiento limitado sobre la actividad del volcán Irazú, 5) la necesidad de recurrir a información vertida por la población, la cual generalmente pasa por el tamiz de la percepción, 6) el hecho de que resultara un evento aislado y efímero que afectó un área poco vulnerable y que, eventualmente, las evidencias condujeran a una conclusión simple y que no requiriera de más comprobación.

Del análisis de la literatura científico-técnica disponible (de la época y más reciente), y de nuevas evidencias, es posible precisar algunos aspectos discutidos por Alvarado et al. (2013) y establecer los siguientes aspectos que sin duda ocurrieron: 1) El arrastre por el viento y posterior caída de pequeños fragmentos de roca y polvo en varias poblaciones del Valle Central, los cuales eran tamaño arena en poblaciones cercanas al volcán Irazú y tamaño polvo fino en los más alejados a este. Este material estaba compuesto por fragmentos de roca hidrotermalizados; 2) los deslizamientos y consecuentes flujos de escombros a lo largo del cauce del Río Sucio; 3) la actividad sísmica que acompañó el proceso y que después de este fue disminuyendo paulatinamente.

Los registros sísmicos de la época muestran gran similitud de las formas de onda asociadas con el evento ocurrido el 8 de diciembre de 1994 y del deslizamiento ocurrido el 17 de diciembre de 2014 (Fig. 9). En ambos casos el inicio de la señal sísmica es emergente y la amplitud aumenta paulatinamente hasta llegar a varias fases de gran amplitud. Otro aspecto interesante es que los dos eventos se registraron en estaciones lejanas. En este mismo sentido, la propuesta de Ulloa et al. (2013) sobre el origen de las cavernas que se ubican en ese lugar, es congruente con el hecho de que los procesos gravitacionales son dominantes en ese sector del macizo.
Sin embargo, queda por abordar tres aspectos:

1. El mecanismo de ese movimiento por cuanto se conjugan varios aspectos, tales como: zonas de debilidad estructural, alteración hidrotermal, la naturaleza misma del material (tefra y lavas). Por lo tanto queda la duda si se trata de un deslizamiento sensu stricto, un volcamiento de rocas, una caída de rocas o bien, una combinación de ellos.

2. El disparador del movimiento. La actividad sísmica intensa generada entre 1990 - 1991 podrían haber coadyuvado a inestabilizar la ladera previamente y la convergencia del enjambre ocurrido en la primera mitad de noviembre de 1994 con las condiciones de precipitación en la vertiente caribe por la influencia de la Tormenta Tropical $\mathrm{N}^{\circ} 12$ y el temporal que se dio en diciembre de 1994, habrían podido desencadenar el proceso. A inicios de noviembre de 1994 se reportaron ruidos que provenían del flanco $\mathrm{N}$ del volcán Irazú (Global Volcanism Program, 1994c), por lo que cabe la posibilidad de que ya hubiese movimientos gravitacionales para ese momento. Adicionalmente, Barquero et al. (1992) describen que aguas debajo de las fumarolas descritas en el sector NW del cráter principal se encontraban los manantiales más altos del área, entre las cotas 2890-2900 m s.n.m., por debajo de las cuales ya no se observaban más fumarolas. Esto les indicaba a dichos autores la presencia de un acuífero superficial del cual se vaporizaba el agua que se movía por encima del nivel freático local. Ulloa et al. (2013), por su parte, reporta la posición de la cueva Los Mucolitos a $2890 \mathrm{~m}$ s.n.m. y la cueva Los Minerales a 2905 m s.n.m., es decir, al mismo nivel de los manantiales que existían en 1991. Esto sugiere que la contribución excesiva de agua a través de los manantiales 

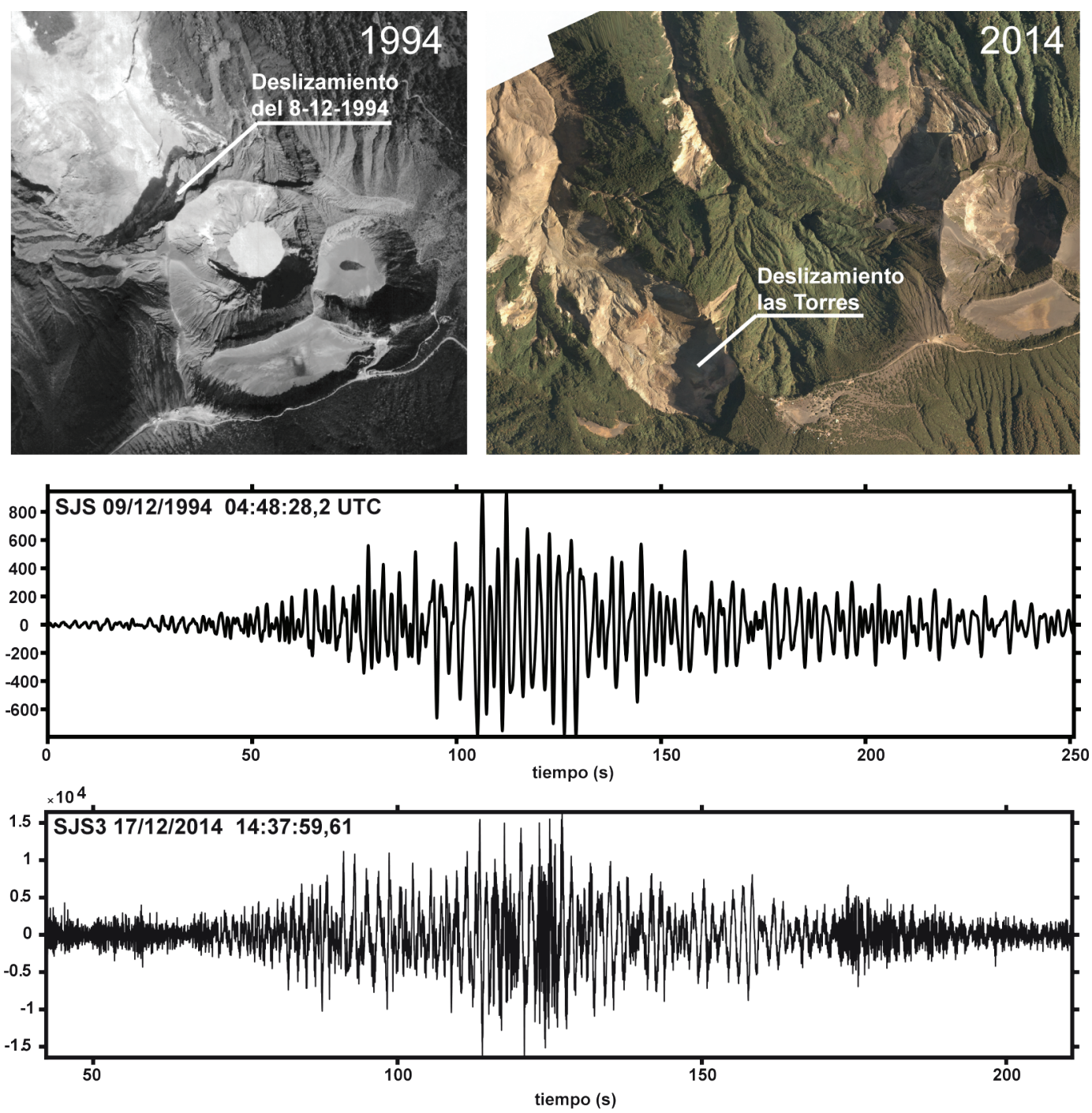

Fig. 9: Arriba: Extractos de las fotografias aéreas de los deslizamientos ocurridos en 1994 (suministrada por el IGN) y 2014 (AERODIVA S.A., 2015). Abajo: Señales sísmicas registradas en la estación San José (SJS) de la Red Sismológica Nacional (RSN: UCR-ICE), ubicada en la Escuela Centroamericana de Geología de la Universidad de Costa Rica. El registro sísmico de 1994 fue obtenido con un sismómetro de periodo corto (1 Hz), en tanto que el registro de 2014 fue obtenido con un sismómetro de banda ancha (30 s).

y la saturación del medio habrían podido socavar la base y debilitar la masa de roca y tefra que posteriormente fue removida violentamente.

3. La tesis de que el proceso sensu stricto se tratara de un movimiento gravitacional, no descarta del todo que el sistema hidrotermal jugara un papel importante en el proceso. El detalle de los sonidos de "motor de jet" que reporta la población que vivía en el flanco norte, sugiere que podría haber ocurrido una desgasificación vigorosa que podría haber sido generada por la descompresión del sistema hidrotermal y, consecuentemente, una explosión dirigida que no se puede precisar si fue antes o después del deslizamiento o, incluso, concomitante. Recuérdese que un testigo afirma que fueron al menos dos eventos principales de "estruendo" (deslizamiento), y que una columna alta de "humo" (material expulsado y levantado) se 
dio en la fase tardía del primer evento. Podría ser que la descompresión por el deslizamiento original, diera cabida a una explosión freática. Aunque los relatos vertidos en la prensa escrita que indican que ya desde el 4 noviembre habrían ocurrido deslizamientos, sugiere fuertemente el bloqueo del campo de fumarolas. Un deslizamiento, por sí solo, no podría haber generado la caída de material relativamente grueso como se reportó en varios lugares. Solo produce finos por molimiento y transporte eólico. Además, al haber tanta agua involucrada en el proceso, el molimiento se da en semilíquido, e inhibe la generación de mucho polvo. En consecuencia, por tanta agua se genera el lahar, y no hay polvo inmiscuido. Habría que invocar, por lo tanto, el hecho de la ocurrencia de una explosión freática inicial o concomitante. En este sentido, también es plausible pensar que, tal como señala RSN (1994b), se pudo acumular presión en el sistema hidrotermal por el bloqueo de las vías principales de desgasificación que consecuentemente generara la explosión y ocurriera un empuje definitivo de la masa rocosa por la presión del gas. Esto es: con base en las evidencias circunstanciales, es posible que sucediera la secuencia explosión-deslizamiento, o bien deslizamiento-explosión-deslizamiento.

Finalmente, vemos que las limitaciones inherentes a las fotografías aéreas de 1994, la falta de los datos de la cámara y de puntos de control de campo, entre otros, generan una incertidumbre importante a la restitución. Pese a ello, el MED resultante es bastante aceptable, aunque claramente debe ser usado con prudencia, lo mismo que el volumen deslizado para el deslizamiento del 8 de diciembre de 1994, el cual se estimó entre $21 \pm 8$ a $22 \pm 7 \times 10^{6} \mathrm{~m}^{3}$. No obstante, es un valor razonable si se considera la incertidumbre y si se compara con los volúmenes obtenidos por Müller et al. (2015) y Mora y Pirulli (2017) para el Deslizamiento las Torres en el volcán Irazú, de $28 \times 10^{6} \mathrm{~m}^{3}$ y $7 \times 10^{6} \mathrm{~m}^{3}$, respectivamente.

\section{CONCLUSIÓN}

La interpretación de lo ocurrido el 8 de diciembre de 1994 en el volcán Irazú todavía queda abierta y es claro que pese a nuevos elementos aportados, no es posible llegar a establecer una secuencia de procesos definitiva que generó la avalancha. Es claro, también, que una investigación más profunda es requerida con el fin de generar modelos geotécnicos adecuados que permitan evaluar la estabilidad de la pared norte del cráter del volcán Irazú, así como la consecuente avalancha de lodo y rocas que podría generarse a lo largo del cauce del río Sucio. En este sentido, el estudio multitemporal de la geomorfología de la cima del volcán y la generación de modelos de elevación digital más precisos, con base tanto en fotografías aéreas históricas como con técnicas modernas (p.e. vuelos aéreos no tripulados) es fundamental.

\section{AGRADECIMIENTOS}

Este artículo es parte del proyecto de investigación titulado "Estudios de deformación en volcanes activos de Costa Rica" $\left(\mathrm{N}^{\circ} 113-\mathrm{B} 1-230\right)$, financiado por la Vicerrectoría de Investigación de la Universidad de Costa Rica. También fue soportado en su última etapa por el proyecto $\mathrm{N}^{\circ} 805-\mathrm{B} 7-286$, apoyado por UCREA, de la Universidad de Costa Rica. Se le agradece a ingeniero topógrafo Kenneth Azofeifa por sus observaciones y comentarios sobre las técnicas de fotogrametría, al geógrafo Rubén Martínez por sus aportes en el manejo de los sistemas de información geográfica, y al estudiante Daniel Rojas por enriquecer este trabajo en el campo fotogramétrico. Se agradece a la empresa AERODIVA S.A. por facilitar las fotografías aéreas y el modelo de elevación digital del volcán Irazú, a través de la Comisión Nacional de Prevención de Riesgos y Atención de Emergencias. Se agradece a Paula Pérez por su ayuda en la elaboración de la Figura 2. Los datos de los puntos geodésicos son contribución del proyecto "Geofísica y geodinámica del arco volcánico en Costa Rica" ( $\left.\mathrm{N}^{\circ} 113-\mathrm{B} 65-\mathrm{A} 00\right)$, financiado por la Vicerrectoría de Investigación de la Universidad de Costa Rica y que fueron obtenidos específicamente en la cima del volcán Irazú por el Dr. Oscar Lücke y Randall Guevara. Se agradece a los revisores por los comentarios que enriquecieron este trabajo. 


\section{REFERENCIAS BIBLIOGRÁFICAS}

AERODIVA S.A. (2015). Informe de producción: vuelo fotogramétrico sobre los volcanes Irazú y Turrialba. San José: AERODIVA S.A. Informe inédito.

Alvarado, G. E. (1987). El volcán Irazú: sintesis geológica, actividad eruptiva y peligro volcánico preliminar. San José: Departamento de Geología, Instituto Costarricense de Electricidad. Informe inédito.

Alvarado, G. E. (1993). Volcanology and petrology of Irazú Volcano, Costa Rica (Tesis de doctorado inédita). Universidad de Kiel, Kiel, Alemania.

Alvarado, G. E. (2009). Los volcanes de Costa Rica: geología, historia y riqueza natural. San José: EUNED.

Alvarado, L. (1994). Resumen meteorológico del mes de diciembre. Boletín Meteorológico Mensual, 2-3.

Alvarado, G. E., Mora, M. M. y Ulloa, A. (2013). La caída de "ceniza" proveniente del Volcán Irazú (Costa Rica) el 8 de diciembre de 1994: ¿una explosión freática? Revista Geológica de América Central, 48, 159-168.

Avard, G., Müller, C., Pacheco, J.F., Martínez, M., De Moor, M., Cascante, M. y Garita, A.L. (2015). Estado de los volcanes de Costa Rica, julio 2015. Recuperado de: http://www.ovsicori.una.ac.cr/index.php/ vulcanologia/estado-de-los-volcanes/ category/4-ev2015

Ávila, L. A. y Rappaport, E. N. (1996). Atlantic hurricane season of 1994. Monthly Weather Review, 124, 1558-1578.

Baldi, P., Fabris, M., Marsella, A. y Monticelli, R. (2005). Monitoring the morphological evolution of the Sciara del Fuoco during the 2002-2003 Stromboli eruption using multi-temporal photogrammetry. ISPRS Journal of Photogrammetry and Remote Sensing, 59(4), 199-211.

Baldi, P., Fabris, M., Marsella, M., Monticelli, R. y Achilli, V. (2006). Application of digital terrain model to volcanology. Annals of Geophysics, 49(4/5), 1059-1066. doi: 10.4401/ag-4409

Baldi, P., Cenni, N., Fabris, M. y Zanutta, A. (2008). Kinematics of a landslide derived from archival photogrammetry and GPS data. Geomorphology, 102, 435-444. doi:10.1016/j.geomorph.2008.04.027

Barquero, J. (1998). Volcán Irazú, Costa Rica. San José: Impreso Lihssa.

Barquero, R. (1992). Los temblores sentidos y actividad volcánica de Costa Rica en 1992. Departamento de Geología, Dirección Ingeniería Civil, Instituto Costarricense de Electricidad. San José: Informe inédito.

Barquero, R., Soto, G. y Lesage, P. (Ed.). (1992). Volcán Irazú, informe vulcanológico enero 1991 - mayo 1992. San José: Oficina de Sismología y Vulcanología, Instituto Costarriense de Electricidad; Universidad de Saboya; CEPREDENAC; Sección de Sismolología, Vulcanolología y Exploración Geofísica, UCR. Informe inédito.

Barquero, R., Mora, M., Madrigal, L., Vargas, I., Arias, F. y Soto, G. (1995a). Resumen anual de sismos y actividad volcánica en Costa Rica durante 1994. San JoséOficina de Sismología y Vulcanología, Instituto Costarricense de Electricidad. Informe indédito.

Barquero, R., Lesage., P., Métaxian, J-P., Creusot, A. y Fernández, M. (1995b). La crisis sísmica en el volcán Irazú en 1991 (Costa 
Rica). Revista Geológica de América Central, 18, 5-18.

Brown, D. C. (1966). Decentering distortion of lenses. Photogrammetric Engineering, 32(3), 444-462.

Capel, J. J. (1996). Los ciclones tropicales en el Atlántico Norte. Papeles de Geografía, 2324, 71-84.

Carr, M. J., Saginor, I., Alvarado, G.E., Bolge, L.L., Lindsay, F.N., Milidakis, K.,...y Swisher III, C.C. (2007). Element fluxes from the volcanic front of Nicaragua and Costa Rica. Geochemistry, Geophysics, Geosystems, 8(6), Q06001. doi:10.1029/2006GC001396.

Chandler, J. H. (1989). The acquisition of spatial data from archival photographs and their application to geomorphology (Tesis de doctorado inédita). The City University, Londres, Inglaterra.

Clark, S. K., Reagan, M. K., y Trimble, D. A. (2006). Tephra deposits for the past 2600 years from Irazú volcano, Costa Rica. En W. I. Rose, G. J. S. Bluth, M. J. Carr, J. W. Ewetrt, L. C. Patino y J. W. Vallance (eds), Volcanic hazards in Central America (pp. 225234). Geological Society of America Special Paper 412. doi: https://dx.doi. org/10.1130/SPE412

Comisión Nacional de Emergencia. (1994). Decreto Ejecutivo 23779-MOPT-MP, Plan regulador para la reconstrucción de los efectos de las inundaciones en el territorio nacional, causados por la depresión tropical $N^{\circ} 12$, Noviembre de 1994. San José: Comisión Nacional de Emergencia. Documento inédito.
Despine, G. (1996). Etudes d'activités induites sur les volcans Taal (Philippines) et Irazú (Costa Rica) par des séismes tectoniques de forte magnitud. Modélisation de séismes et calculs des contraintes dynamiques et etatiques générées pas ces séismes (Memoria de Diploma de Estudios a Profundidad inédita). Université Joseph Fourier y Université de Savoie, Francia.

Escarcena, J., Mata, E., Pérez, J. L., Delgado García, J., González, A., Díaz J. R. y Olague, I. (2008). Detección y cuantificación de cambios geomorfológicos a partir del análisis de vuelos históricos. GeoFocus, 9, 150-165.

Environmental Systems Research Institute [ESRI], Inc. (2016). ArcGIS Help. Recuperado de: http://resources.arcgis.com/en/help/main/10.1/index. html\#//009t00000042000000

Fabris, M., Menin, A. y Achilli, V. (2011). Landslide displacement estimation by archival digital photogrammetry. Italian Journal of Remote Sensing, 43(2), 23-30.

Fallas, J. C. y Oviedo. R. (2003). Fenómenos atmosféricos y cambio climático, visión centroamericana. San José: Instituto Meteorológico Nacional.

Fernández, E., Barquero, J., Barboza, V., Van Der Laat, R., Malavassi, E., Sáenz, R.,... Martínez, M. (1994). Estado de los volcanes. Boletín de Vulcanología, Sismología y Tectónica, 1-7.

Fernández, M., Mora, M. y Barquero, R. (1998). Los procesos sísmicos en el Volcán Irazú. Revista Geológica de América Central, 21, 47-59. 
Galindo, I., Melián, G., Salazar, J.M., Hernández, P., Pérez, N., Ramírez, C... y Notsu, K. (2004). Emisión difusa de dióxido de carbono en el volcán Irazú. Revista Geológica de América Central, 30, 157-165.

Gawarecki, S.J., Moxham, P.M., Morgan, J.Q., y Parker, D.C. (1980). An infrared survey of Irazu volcano and vicinity, Costa Rica. Proceedings of the $14^{\text {th }}$ International Symposium on Remote Sensing of the Environment, San José, Costa Rica, Abril 23-30 1980, pp. 1901-1912.

Global Volcanism Program. (1991). Report on Irazú (Costa Rica). Bulletin of the Global Volcanism Network, 16(6). Recuperado de: http://dx.doi.org/10.5479/si.GVP. BGVN199106-345060

Global Volcanism Program. (1994a). Report on Irazú (Costa Rica). Bulletin of the Global Volcanism Network, 19, 1. Recuperado de: http://dx.doi.org/10.5479/si.GVP. BGVN199401-345060

Global Volcanism Program. (1994b). Report on Irazú (Costa Rica). En: Wunderman, R (ed.), Bulletin of the Global Volcanism Network, 19, 11. Recuperado de: http:// dx.doi.org/10.5479/si.GVP.BGVN199411345060

Global Volcanism Program. (1994c). Report on Irazú (Costa Rica). Bulletin of the Global Volcanism Network, 19, 12. Recuperado de: http://dx.doi.org/10.5479/si.GVP. BGVN199412-345060.

Gross, P., Van Wyk de Vries, B., Petrinovic, I. A., Eullades P. y Alvarado, G. E. (2009). Morphometry and evolution of arc volcanoes. Geology, 37(7), 651-654. doi: 10.1130/G25734A.1
Halpert, M. S., Bell, G. D., Kousky, V. E., y Ropelewski, C. F. (ed). (1995). Climate assessment for 1994. Camp Springs, USA: Climate Analysis Center. Informe inédito.

INTERGRAPH. (2013). ERDAS Field GuideTM: Security, Government \& Infrastructure. Huntsville, USA: Intergraph Corporation.

Instituto Costarricense de Electricidad [ICE], (1994). La erupción freática del Irazú, 8 de diciembre de 1994 causas, hechos y consecuencias. San José: Oficina de Sismología y Vulcanología, Instituto Costarricense de Electricidad. Informe inédito.

Linkimer, L. (2003). Neotectónica del extremo oriental del cinturón deformado del centro de Costa Rica (Tesis de licenciatura inédita). Universidad de Costa Rica, San José, Costa Rica.

Micheletti, N., Lane, S. N., y Chandler, J. H. (2015). Application of archival aerial photogrammetry to quantify climate forcing of alpine landscapes. Photogrammetric Record, 30(150), 143-465.

Mikrut, S. (2008). Experience from the utilisation of archival aerial images for needs of database feeding. Geomatics and Environmental Engineering, 2(2), 69-80.

Montero, W. y Alvarado, G. E. (1995). El Terremoto de Patillos del 30 de diciembre de $1952(\mathrm{Ms}=5,9)$ y el contexto neotectónico de la región del volcán Irazú, Costa Rica. Revista Geológica de América Central, 18, 25-42.

Montero, W. (2003). El sistema de falla AtirroRío Sucio y la cuenca de tracción de Turrialba-Irazú: Indentación tectónica relacionada con la colisión del levanta- 
miento del Coco. Revista Geológica de América Central, 28, 5-29.

Mora, M., Ash, C., Oconitrillo, G. y Salazar, L. (1996). Amenaza y vulnerabilidad en el flanco norte del volcán Irazú: explosión de diciembre de 1994, un caso específico. Presentado en el $I V$ Simposio Latinoamericano sobre Riesgos Geológicos en Áreas Urbanas, San José, Costa Rica, 9-13 Setiembre 1996, pp. 58.

Mora, M., Barquero, R., Rojas, W. y Fernández, M. (1997). El enjambre sísmico del volcán Irazú, Junio 1997. San José: Oficina de Sismología y Volcanología, Instituto Costarricense de Electricidad. Informe inédito.

Mora, M. (1997). Informe sobre la actividad de los volcanes Poás e Irazú 1994-1996. San José: Red Sismológica Nacional (RSN: ICE-UCR). Informe inédito.

Mora, M. M., Taylor, W. y Soto, G. J. (2012). Sismicidad inducida y otros efectos causados en el arco magmático. En L. Linkimer, y G. Soto (eds), El Terremoto de Sámara del 5 de setiembre de 2012 (pp. 59-61). San José: Red Sismológica Nacional (ICEUCR). Informe inédito.

Mora, R. y Pirulli, M. (2017). Deslizamiento Las Torres, volcán Irazú, Costa Rica: definición de su volumen y su dirección preferencial de movimiento. Revista. Geológica de América Central, 56, 51-67.

Müller, C., Pacheco, J., Avard, G. y Martínez, M. (2015). Estado de los Volcanes de Costa Rica. Boletín de Vulcanología. Recuperado de: http://www.ovsicori.una.ac.cr/index. $\mathrm{php} /$ vulcanologia/estado-de-los-volcanes/ category/4-ev2015

Müeller, P. W., y Hoffer, R. N. (1989). Low-pass spatial filtering of satellite radar data. Photogrammetric Engineering and Remote Sensing, 55(6), 887-895.

Paniagua, S. (1994). Sintesis de la actividad reciente del volcán Irazú. San José: Red Sismológica Nacional (ICE-UCR). Informe inédito.

Peraldo, G. y Rojas, E. (2000). Catálogo de deslizamientos de Costa Rica, 1772 -1960. Informe Semestral del Instituto Geográfico Nacional, 36, 123-171.

Pitts, P.A. (2001). Interactions between Florida Bay and Atlantic Shelf Waters in Response to Tropical Storm Gordon. Estuarine, Coastal and Shelf Science, 52(1), 225-235. doi:10.1006/ecss.2000.0738.

Quirós, A. (1910). Comunicado al Ministro de Gobernación. Fondo José Fidel Tristán, expediente código CR-ANAH-FITRIS-000019, signatura 000019, folio $4 \mathrm{f}$.

Quirós, E. (2014). Introducción a la fotogrametría y cartografía aplicadas a la ingeniería civil. Cáceres, España: Universidad de Extremadura, Servicio de Publicaciones.

RED SISMOLÓGICA NACIONAL (RSN: ICEUCR). (1994a). Resumen de actividad sísmica y volcánica. Periodo de EneroDiciembre de 1993. Revista Geológica de América Central, 17, 105-107. 
RED SISMOLÓGICA NACIONAL (RSN: ICEUCR). (1994b). Informe sobre actividad del volcán Irazú. San José: Red Sismológica Nacional (ICE-UCR). Informe inédito.

Sánchez, A. (12 de diciembre de 1994a). Erupción del Irazú dejó un gran hoyo. La República, p. 10A.

Sánchez, A. (13 de diciembre de 1994b). Ruge el coloso. La República, p. 4A.

Siebert, L., Simkin, T. y Kimberly, P. (2010). Volcanoes of the World. Berkeley and Los Angeles, California: University of California Press.

Soto, G. J. (1994). Volcanología física. En P. Denyer y S. Kussmaul (comps.), Atlas geológico Gran Área Metropolitana (pp. 131-146). Cartago: Editorial Tecnológica de Costa Rica.

Soto, G. J. y Sjöbohm, L. (2015). Escenarios de amenaza del volcán Irazú (Costa Rica): una aproximación preliminar. San José, Costa Rica: FUNDEVI. Informe inédito.

Tristán, J. F. (1910). Cuaderno de apuntes con descripción de las diferentes manifestaciones sísmicas del volcán Irazú. Fondo José Fidel Tristán, expediente código CR-ANAH-FITRIS-000048, signatura 000048, folios 14-15f.

Tristán, J. F. (1921). El Irazú activo. En: Obregón, M., Nociones de Geografía Patria. Tomo I. Geografía física de la América Central (pp. 123-127). San José, Costa Rica: Imprenta Nacional.
Tristán, J. F. y Rudín, A. (1910). Lugares poco conocidos del volcán Irazú. San José:Archivo Nacional. Documento inédito.(Fondo José Fidel Tristán, expediente código CR-ANAH-FITRIS-000025, signatura 0025).

Ulloa, A., Campos-Fernández, C.S. y Rojas, L. (2013). Cueva Los Minerales, volcán Irazú, Costa Rica: descripción, mineralogía y origen. Revista Geológica de América Central, 48, 169-187.

Vales, J. J., Carpintero, I. R., Granado, L., Méndez, E., Montoya, G., Pino, R.,...y Moreira, J. M. (2010). Producción de ortofotos históricas para la generación de bases de datos temáticas. Cartografía de usos y coberturas del suelo. REDIAM. En J. Ojeda, M. F. Pita y I. Vallejo (eds), Tecnologías de la información geográfica: la información geográfica al servicio de los ciudadanos (pp. 370-384). Sevilla, España: Secretariado de Publicaciones de la Universidad de Sevilla.

Vega, G. (1994). Resumen meteorológico del mes de noviembre. Boletín Meteorológico Mensual, 2-3.

Walstra, J., Chandler, J. H., Dixon, N. y Dijkstra, T. A. (2004). Time for change - quantifying landslide evolution using historical aerial photographs and modern photogrammetric methods. International Archives of Photogrammetry, Remote Sensing and Spatial Information Sciences, 35(B4), 475480.

Walstra, J., Dixon, N. y Chandler, J.H. (2007). Historical aerial photographs for landslide assesment: two case histories. Quaterly 
Journal of Engineering Geology and Hydrogeology, 40, 315-332.

Zanutta, A., Baldi, P., Bitelli, G., Cardinali, M. y Carrara, A. (2006). Qualitative and quantitative photogrammetric techniques for multi-temporal landslide analysis. Annals of Geophysics, 49(4/5), 1067-1080.

Zárate, E. (2013). Climatología de masas invernales de aire frío que alcanzan Centroamérica y el Caribe y su relación con algunos índices Árticos. Tópicos Meteorológicos y Oceanográficos, 12(1), $35-55$.

Zlotnicki, J., Ruegg, J. C., Bacheley P. y Blum, P. (1990). Eruptive mechanism on Piton de la Fournaise volcano associated with the December 4, 1983, and January 18, 1984 eruption from ground deformation monitoring and photogrammetric surveys. Journal of Volcanology and Geothermal Research, 40, 197-217. 